\title{
Silencing PRDM14 expression by an innovative RNAi therapy inhibits stemness, tumorigenicity, and metastasis of breast cancer
}

\author{
Hiroaki Taniguchi ${ }^{1}$, Daisuke Hoshino ${ }^{2}$, Chiharu Moriya ${ }^{1}$, Hitoshi Zembutsu ${ }^{3}$, \\ Nobuhiro Nishiyama ${ }^{4}$, Hiroyuki Yamamoto ${ }^{5}$, Kazunori Kataoka ${ }^{6}$ and Kohzoh Imai ${ }^{1,7}$ \\ ${ }^{1}$ The Center for Antibody and Vaccine Therapy, Research Hospital, The Institute of Medical Science, The University of Tokyo, \\ Tokyo 108-8639, Japan \\ ${ }^{2}$ Cancer Biology Department, The Kanagawa Cancer Center Research Institute, Kanagawa 241-0815, Japan \\ ${ }^{3}$ Division of Genetics, National Cancer Center Research Institute, Tokyo 104-0045, Japan \\ ${ }^{4}$ Polymer Chemistry Division, Chemical Resources Laboratory, Tokyo Institute of Technology, Kanagawa 226-8503, Japan \\ ${ }^{5}$ Department of Gastroenterology and Hepatology, School of Medicine, St. Marianna Medical University, Kanagawa 216-0015, \\ Japan \\ ${ }^{6}$ Department of Materials Engineering, Graduate School of Engineering, The University of Tokyo, Tokyo 113-8656, Japan \\ ${ }^{7}$ The Institute of Medical Science, The University of Tokyo, Tokyo 108-8639, Japan \\ Correspondence to: Hiroaki Taniguchi, email: h-tani@ims.u-tokyo.ac.jp
}

Keywords: breast cancer stem cell, cancer stemness, epigenetic alterations, nucleic acid medicine, PRDM14

Received: November 11, $2016 \quad$ Accepted: March 22, $2017 \quad$ Published: April 01, 2017

Copyright: Taniguchi et al. This is an open-access article distributed under the terms of the Creative Commons Attribution License 3.0 (CC BY 3.0), which permits unrestricted use, distribution, and reproduction in any medium, provided the original author and source are credited.

\section{ABSTRACT}

PR domain zinc finger protein 14 (PRDM14) maintains stemness in embryonic stem cells via epigenetic mechanisms. Although PRDM14 is elevated in several cancers, it is unclear if and how PRDM14 confers stem cell-like properties and epigenetic changes to cancer cells. Here, we examined the phenotypic characteristics and epigenetic and gene expression profiles of cancer cells that differentially express PRDM14, and assessed the potential of PRDM14-targeted cancer therapy. PRDM14 expression was markedly increased in many different cancer types and correlated with poor survival of breast cancer patients. PRDM14 conferred stem cell-like phenotypes to cancer cells and regulated the expression of genes involved in cancer stemness, metastasis, and chemoresistance. PRDM14 also reduced the methylation of protooncogene and stemness gene promoters and PRDM14-binding regions were primarily occupied by histone H3 Lys-4 trimethylation (H3K4me3), both of which are positively correlated with gene expression. Moreover, strong PRDM14 binding sites coincided with promoters containing both $\mathrm{H} 3 \mathrm{~K} 4 \mathrm{me} 3$ and $\mathrm{H} 3 \mathrm{~K} 27 \mathrm{me} 3$ histone marks. Using calcium phosphate hybrid micelles as an RNAi delivery system, silencing of PRDM14 expression by chimera RNAi reduced tumor size and metastasis in vivo without causing adverse effects. Conditional loss of PRDM14 function also improved survival of MMTV-Wnt-1 transgenic mice, a spontaneous model of murine breast cancer. Our findings suggest that PRDM14 inhibition may be an effective and novel therapy for cancer stem cells.

\section{INTRODUCTION}

Cancer stem cells (CSCs) comprise a small population of tumor cells that resist chemotherapeutic agents and impart oncogenic phenotypes, including metastatic capability.
CSCs are therefore important therapeutic targets [1, 2]. The first CSCs to be discovered in solid tumors were tumorigenic $\mathrm{CD} 44^{+} / \mathrm{CD} 24^{- \text {llow }}$ breast cancer cells in severe combined immunodeficiency mice [3]. CSCs have subsequently been isolated from many other solid tumors [1]. 
PRDI-BF1 and RIZ (PR) domain zinc finger protein 14 (PRDM14) is specifically expressed in embryonic stem (ES) cells and primordial germ cells [4, 5] and, together with other factors, promotes ES cell pluripotency. PRDM14 recruits polycomb repressive complex 2 to target genes and suppresses de novo methyltransferases that convert the epigenome to a primed epiblast-like state [5]. PRDM14 directly binds to the proximal enhancer region of the POU5F1 gene and upregulates OCT4 (encoded by the POU5F1 gene) expression and colocalizes with other master regulators of pluripotency (e.g., SOX2 and NANOG) in human ES cells [6].

PRDM14 contains a PR domain homologous to the SET domain of histone lysine (Lys) methyltransferases, which regulates cell differentiation [7-9]. Epigenetic alterations such as histone modification and DNA methylation play key roles in ES cell differentiation and oncogenic pathways in cancer cells. ES cells contain many 'poised' bivalent chromatin domains comprising both 'activating' histone H3 Lys-4 trimethylation (H3K4me3) and 'repressive' histone H3 Lys-27 trimethylation (H3K27me3) modifications in the promoters of developmental regulatory genes [10]. When ES cells commit to a particular differentiation lineage and poised genes are activated, the 'repressive' $\mathrm{H} 3 \mathrm{~K} 27 \mathrm{me} 3$ mark is removed and the 'activating' $\mathrm{H} 3 \mathrm{~K} 4 \mathrm{me} 3$ mark is retained, and RNA polymerase II ( $\mathrm{Pol}$ II) is simultaneously activated. In contrast, bivalent domains of genes associated with other lineages are silenced by retaining the H3K27me3 mark, and occurrence of H3K9me3 and DNA methylation in their promoter. In many tumors, aberrant DNA methylation is observed in the $\mathrm{CpG}$ island promoter around the transcription start sites (TSSs) of tumor suppressor genes, the expressions of which are silenced by DNA hypermethylation.

Previously, we showed that PRDM14 is elevated in two-thirds of breast cancers, some of which exhibit gene amplification on chromosome 8q13.3 [11]. Elevated PRDM14 expression is also associated with acute lymphatic leukemia and lung carcinoma $[12,13]$. In contrast, PRDM14 is not expressed in normal differentiated tissues [11-13].

Genes that are overexpressed in cancers, such as PRDM14, may be effective targets for new therapies. Further, small interfering RNAs (siRNAs) have considerable potential as therapeutic agents for overexpressed genes. However, when administered by systemic injection, siRNAs are easily degraded by nucleases in the blood, are filtered by the kidney, accumulate poorly in target sites, and activate the innate immune system. Furthermore, siRNAs cannot readily diffuse across cell membranes and must escape from endosomes to reach their targeted mRNAs. Efforts to develop next-generation siRNA delivery strategies include modification of siRNAs and drug delivery systems (DDSs). The combination of small interfering RNA/DNA chimera (chimera RNAi) [14-16] with calcium phosphate (CaP) hybrid micelles [17] as a DDS can overcome many of the barriers encountered by standard systemic delivery systems. CaP hybrid micelles are stealth nanoparticles comprised of a CaP-nucleic acid core surrounded by a coating of polyethylene glycol (PEG)-polyanion block copolymers. The polyanion segment acts as a binding moiety with $\mathrm{CaP}$ nanoparticles while the PEG segment reduces non-specific interactions in the bloodstream. $\mathrm{CaP}$ hybrid micelles accumulate in solid tumors through enhanced permeability and retention (EPR) effects as a result of their narrow diameter distribution (30-40 nm). Further, the polyanion segment confers sensitivity to acidic $\mathrm{pH}$, thereby enhancing delivery efficiency and permitting endosomal escape after endocytic internalization [17]. Therapeutic chimera RNAi can avoid off-target effects due to RISC formation of the sense strand, and has exhibited excellent stability in the bloodstream and low immunogenicity in vivo [14-16].

Here, we examined whether PRDM14 induces CSC-like phenotypes and influences the epigenetic state of cancer cells. Given the high PRDM14 expression in tumors and its ability to mediate pluripotency in ES cells, we hypothesized that PRDM14 contributes to CSC formation and aberrant epigenetic status in cancer. We further examined the potential of a novel breast cancer therapy that modifies PRDM14 expression using an innovative RNAi system - chimera RNAi with CaP hybrid micelles - by systemic injection. Since PRDM14 is regulated by Wnt signaling in mouse ES cells [18,19], we validated that the therapeutic effects of silencing PRDM14 were indeed due to PRDM14 deletion in mammary tumor virus (MMTV)-Wnt-1 mice, which ectopically express Wnt and have a high incidence of spontaneous mammary adenocarcinomas containing CSC fractions [20, 21].

\section{RESULTS}

\section{PRDM14 expression in human tumors}

PRDM14 mRNA was markedly upregulated in breast, lung, esophagus, pancreas, ovary, kidney, bladder, and testicular cancers compared to expression in the respective normal tissues (Figure 1A). PRDM14 mRNA expression was 3-fold higher in 55.1\% (97/176) of breast cancer tissues compared to normal mammary tissues obtained from 10 patients (Figure 1B).

Similarly, immunohistochemical analyses using tissue microarrays showed that PRDM14 protein was expressed in tumor tissues for breast cancer, $35.9 \%(n=14$ out of 39 cases); lung cancer, 25.6\% (10/39); pancreatic cancer, 29.3\% (49/167); ovarian cancer, 37.3\% (19/51); renal cancer, $38.8 \%$ (19/49); prostate cancer, $15.4 \%$ (6/39); testicular cancer, 7.0\% (6/86); and cervical cancer, $18.4 \%$ (9/49). PRDM14 protein was not expressed in the corresponding normal tissues (Figure 1C). 


\section{PRDM14 expression in breast cancer}

Immunohistochemical analyses showed PRDM14 protein in $37.1 \%(79 / 213)$ of breast cancer patients. PRDM14 expression and patient clinicopathologic characteristics are summarized in Table 1. Tumors at stages 0 , I, II, III, and IV expressed PRDM14 at frequencies of $50.0 \%(12 / 24), 28.1 \%(16 / 57), 38.9 \%$ (28/72), 40.5\% (17/42), and 33.3\% (6/18), respectively. There was no significant correlation between PRDM14 expression and disease stage.

PRDM14 expression was inversely correlated with estrogen receptor expression $(\rho=-0.33, P<$ 0.001 ), a marker of breast tumor differentiation, and showed no association with progesterone receptor ( $\rho=0.15, P=0.95)$ or human epidermal growth factor receptor (HER)-2 expression $(\rho=-0.09, P=$ $0.55)$. PRDM $14^{+}$breast cancer cells were positive for cytokeratin (CK) 5 and negative for CK 8 expression (CK5: $\rho=0.40, P<0.001$; CK8: $\rho=-0.62, P<0.001$ ). PRDM14 expression was also significantly negatively correlated with lymphocyte infiltration in tumors $(\rho=-0.52, P<0.001)$ : PRDM14-negative breast cancer tissues exhibited increased numbers of tumorinfiltrating cytotoxic $\mathrm{T}$ lymphocytes $\left(\mathrm{CD}^{+} \mathrm{CD} 8^{+} \mathrm{CD} 16^{-}\right)$. Since mammary stem cells do not express the estrogen receptor or CK8, but do express CK5/6 [22,23], our results indicate that $\mathrm{PRDM}_{14}{ }^{+}$breast cancer cells possess features of mammary stem cell phenotypes. PRDM14 was detected at varying levels in tumorigenic breast cancer cell lines, but was not present in the non-tumorigenic MCF-10A line derived from benign proliferative breast tissue (Figure 1D, 1E).

Survival analysis on 40 tissue samples (high PRDM14 levels: $\mathrm{n}=21$ samples (stage II: $\mathrm{n}=12$, stage III: $n=9$ ), low or undetectable levels: $\mathrm{n}=19$ (stage II: $n=11$, stage III: $n=8)$ ) from breast cancer patients showed that PRDM14 ${ }^{+}$patients had worse prognoses than PRDM14 patients (Figure 1F).

\section{Effect of PRDM14 on stemness phenotype}

We generated three breast cancer cell lines (MCF7, MDA-MB-231, and HCC1937) and a non-tumorigenic MCF-10A cell line overexpressing FLAG-tagged PRDM14 (Supplementary Figure 1A) to examine the functions of PRDM14 in vitro and in vivo.

PRDM14 overexpression in these cells did not increase the cell proliferation rate or colony numbers in vitro (Supplementary Figure 1B, 1C). We also used sphere formation assays to isolate cell subsets enriched with CSCs from solid tumors and assess the self-renewal ability of tumor cells [1]. PRDM14 overexpression promoted sphere formation and increased levels of the stem cell markers Oct3/4, SOX-2, SSEA1, and SSEA4 (Figure 2A, 2B, Supplementary Figure 1D, 1E).
We also established primary cultures of breast cancer cells derived from the initial site of invasive breast cancers from patients with luminal-type (LBC-1, LBC-2, and LBC-5) and basal-type (BBC-4) cancers. We used single-cell suspensions of each primary culture to establish secondary tumorsphere cultures and analyzed the mRNA level in viable cells (Supplementary Figure 1F). PRDM14 expression was higher in tumorspheres than in monolayers established from the same cells (Figure 2C). Moreover, these tumorspheres were enriched in tumorigenic $\mathrm{CD} 44^{+}$/ CD24-low cells (Supplementary Figure $1 \mathrm{G}$ ).

The side-population phenotype is characteristic of CSCs and is associated with drug resistance [24]. Side-population cells can strongly efflux Hoechst 33342 dye due to the actions of ATP-binding cassette (ABC) transporters $[24,25]$. The side-population phenotype was more prominent in PRDM14-expressing cells compared to control, and was inhibited by treatment with reserpine, an $\mathrm{ABC}$ transporter inhibitor (Figure 2D). These data indicate that PRDM14 expression induces stemness characteristics, including tumorsphere formation, cell plasticity, and the presence of a side-population phenotype.

To assess the tumorigenic potential of cells expressing PRDM14, we orthotopically grafted nude mice with PRDM14-overexpressing MDA-MB-231 and HCC1937 cells. Mice engrafted with PRDM14 transfectants had bigger tumors compared to mocktransfected controls (Figure 2E, 2F, Supplementary Figure 1H). PRDM14-transfected cells metastasized to the lymph nodes and lungs (Figure 2E, 2G, 2H). PRDM14expressing tumors also exhibited decreased apoptosis and higher vascular density than tumors induced by mocktransfected cells (Figure 2I, 2J).

Based on these findings, we assessed the metastatic potential of PRDM14-expressing tumor cells in vivo by injecting MDA-MB-231 cells through the tail vein of nude mice. Multiple large metastases were observed in the lungs of mice injected with a PRDM14 versus mock transfectant (Supplementary Figure 1I, 1J).

These results indicate that, although PRDM14 expression did not induce cell proliferation in vitro, PRDM14 overexpression accelerated tumor growth, metastasis, angiogenesis, and resistance to apoptosis in vivo.

\section{Effect of PRDM14 on gene expression}

To determine pathway-/disease-specific genes regulated by PRDM14, we used qRT-PCR array analyses to select genes that showed $>1.5$-fold differential expression in the four cell lines that overexpress PRDM14 (MDA-MB-231, MCF7, HCC1937, and MCF10A). Upregulated genes included members of the tumor necrosis factor superfamily (TNFRSF9, TNFRSF11B, and $T N F S F 8), \mathrm{ABC}$ transporters ( $A B C B 1$ and $A B C G 2)$, and nuclear factor (NF)-kB-related genes (NFKB2 and RELB), all of which induce stemness in cancer cells [24, 26-27]. 
Table 1: Correlation between human PRDM14 expression and clinicopathological characteristics of patients with breast cancer treated at the Kanagawa Cancer Research and Information Association (KCRIA)

\begin{tabular}{|c|c|c|c|}
\hline & PRDM14- $n(\%)$ & PRDM14+ $n(\%)$ & $p$ value \\
\hline \multicolumn{4}{|l|}{ Age (years) } \\
\hline $20-40$ & $6(50.0 \%)$ & $6(50.0 \%)$ & \multirow{3}{*}{$0.49(-60$ vs $61-)$} \\
\hline $41-60$ & $62(59.6 \%)$ & $42(40.4 \%)$ & \\
\hline$\geq 61$ & $60(61.9 \%)$ & $37(38.1 \%)$ & \\
\hline \multicolumn{4}{|l|}{ Clinical stage } \\
\hline stage 0 & $12(50.0 \%)$ & $12(50.0 \%)$ & \multirow{8}{*}{0.63 (stage 0, I vs stage II $\sim$ IV) } \\
\hline stage I & $41(71.9 \%)$ & $16(28.1 \%)$ & \\
\hline stage IIA & $26(63.4 \%)$ & $15(36.6 \%)$ & \\
\hline stage IIB & $19(61.3 \%)$ & $12(38.7 \%)$ & \\
\hline stage IIIA & $9(56.3 \%)$ & $7(43.7 \%)$ & \\
\hline stage IIIB & $9(64.3 \%)$ & $5(35.7 \%)$ & \\
\hline stage IIIC & $8(66.7 \%)$ & $4(33.3 \%)$ & \\
\hline stage IV & $11(61.1 \%)$ & $7(38.9 \%)$ & \\
\hline \multicolumn{4}{|c|}{ Estrogen receptor } \\
\hline- & $23(33.3 \%)$ & $46(66.7 \%)$ & \multirow{2}{*}{$<0.001$} \\
\hline+ & $97(67.4 \%)$ & $47(32.6 \%)$ & \\
\hline \multicolumn{4}{|c|}{ Progesterone receptor } \\
\hline- & $53(49.5 \%)$ & $54(50.5 \%)$ & \multirow{2}{*}{0.95} \\
\hline+ & $54(50.9 \%)$ & $52(49.1 \%)$ & \\
\hline \multicolumn{4}{|l|}{ Hercep test* } \\
\hline- & $59(62.1 \%)$ & $36(37.9 \%)$ & \multirow{5}{*}{$0.55(-$ vs $1+\sim 3+)$} \\
\hline $1+$ & $38(61.3 \%)$ & $24(38.7 \%)$ & \\
\hline $2+$ & $14(58.3 \%)$ & $10(41.7 \%)$ & \\
\hline $3+$ & $24(82.8 \%)$ & $5(17.2 \%)$ & \\
\hline N.D. & $2(66.6 \%)$ & $1(33.3 \%)$ & \\
\hline \multicolumn{4}{|l|}{ CK5 } \\
\hline- & $56(39.4 \%)$ & $86(60.6 \%)$ & \multirow{2}{*}{$<0.001$} \\
\hline+ & $1(1.4 \%)$ & $70(98.6 \%)$ & \\
\hline \multicolumn{4}{|l|}{ CK8 } \\
\hline- & $12(8.2 \%)$ & $134(91.8 \%)$ & \multirow{2}{*}{$<0.001$} \\
\hline+ & $45(67.2 \%)$ & $22(32.8 \%)$ & \\
\hline \multicolumn{4}{|c|}{ Infiltrating lymphocytes } \\
\hline- & $54(42.2 \%)$ & $74(57.8 \%)$ & \multirow{2}{*}{$<0.001$} \\
\hline+ & $80(94.1 \%)$ & $5(5.9 \%)$ & \\
\hline
\end{tabular}

*Hercep test is an FDA-approved immunohistochemical assay for the detection of HER2 protein overexpression in breast and gastric cancer.

We also detected upregulation of genes involved in cancer metastasis and cancer stemness (FOXC2, SNAI2, CXCRs, and $I G F 1$ ), cell stemness (NANOG, POU5F1, and KLF4), metalloproteinases (MMP7, MMP10, and $M M P 13)$, and angiogenic factors (IL-8 and SIPRI) (Supplementary Table 1).
Inhibiting PRDM14 expression in MCF7 and HCC1937 cells (Supplementary Figure 2A and 2B) reduced transcription of many genes that were upregulated by PRDM14 overexpression. Downregulated genes ( $>$ 3-fold) had functions in breast cancer (cathepsin D, KRT5, and MAPK1), apoptosis (TNFSF8), drug resistance 

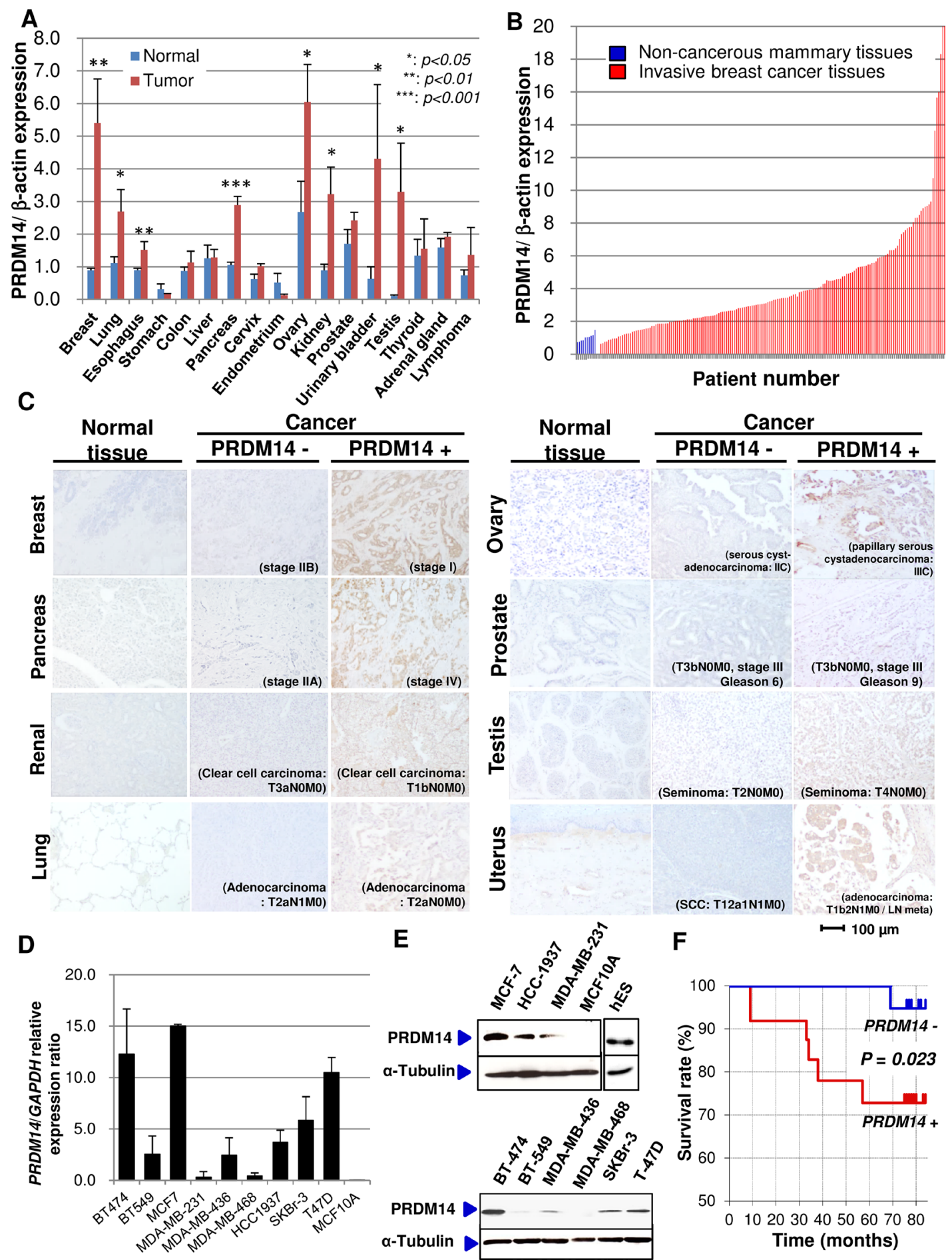

Figure 1: PRDM14 expression in cancer tissues. (A) qRT-PCR analyses of PRDM14 transcripts in different types of cancers compared to expression in respective normal tissues. Clinical samples: breast (normal/tumor [N/T], 4/24), lung (N/T, 4/19), esophageal (N/T, 3/18), stomach (N/T, 5/14), colon (N/T, 7/13), liver (N/T, 3/17), pancreatic (N/T, 5/17), cervical (N/T, 4/9), uterine (N/T, 4/17), ovarian (N/T, 3/21), renal (N/T, 5/18), prostate (N/T, 5/21), bladder (N/T, 2/22), testicular (N/T, 6/19), thyroid (N/T, 3/18), adrenal gland (N/T, 5/10), and lymphoma (N/T, 3/34). (B) qRT-PCR analyses of PRDM14 transcripts in breast cancer and normal mammary tissues. Tissues from 177 invasive ductal breast carcinomas and 10 normal mammary glands. (C) Immunohistochemical expression of PRDM14 in different types of benign and cancerous tissues. Scale bar, $100 \mu \mathrm{m}$. (D) qRT-PCR analysis of PRDM14 mRNA expression in breast cancer cell lines. Data are expressed as mean \pm standard deviation $(n=3)$. (E) Immunoblot analyses of PRDM14 and $\alpha$-tubulin expression in breast cancer cell lines. A lysate prepared from human embryonic stem (hES) cells served as a positive control. (F) Kaplan-Meier plots of the survival in breast cancer patients $(n=40)$. PRDM14-, expression scores 0-2 $(n=19)$; PRDM14+, expression scores 3-4 $(n=21)$. The $P$ value from the log rank test is shown. 
A

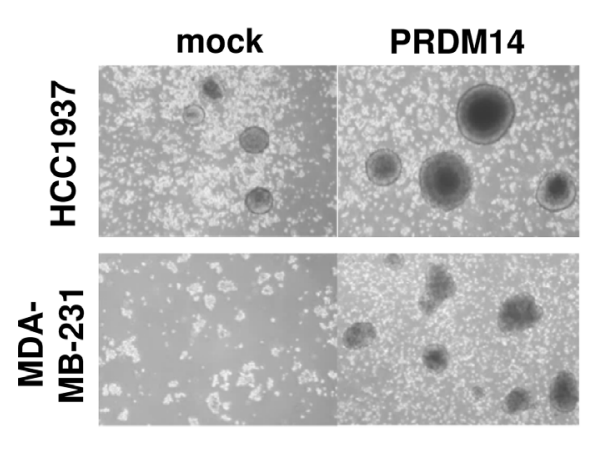

B

Oct3/4

SSEA1

SSEA4

E

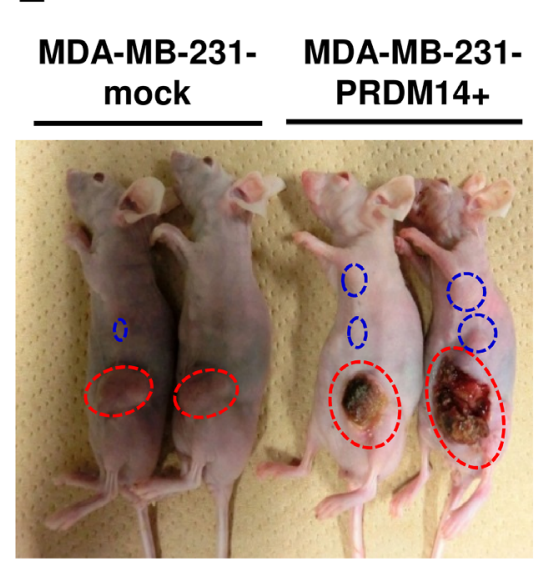

H

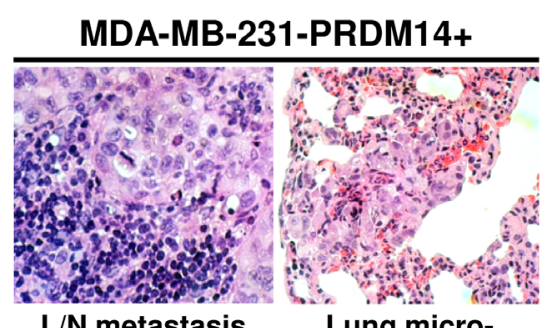

L/N metastasis
C
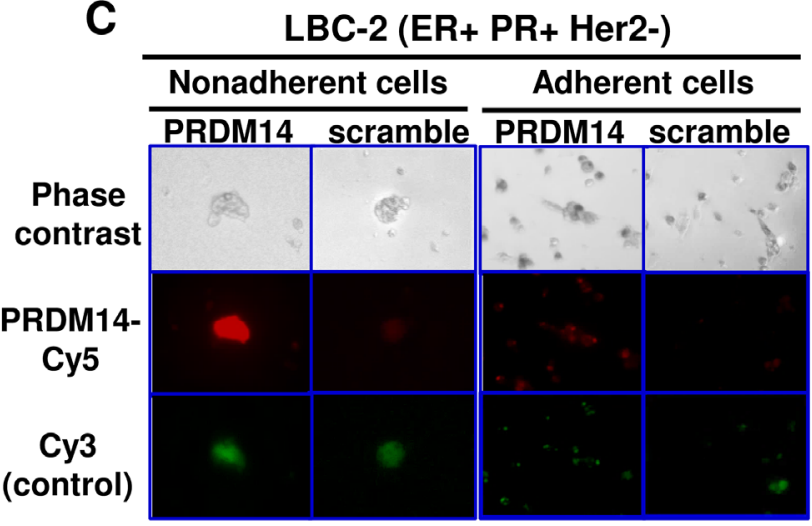

D

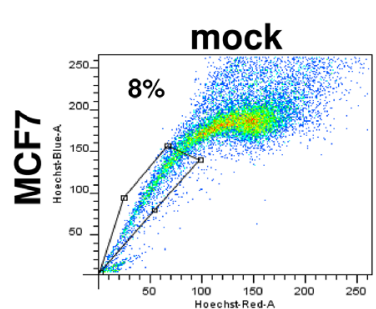

PRDM14

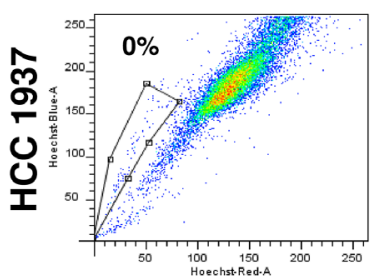

F

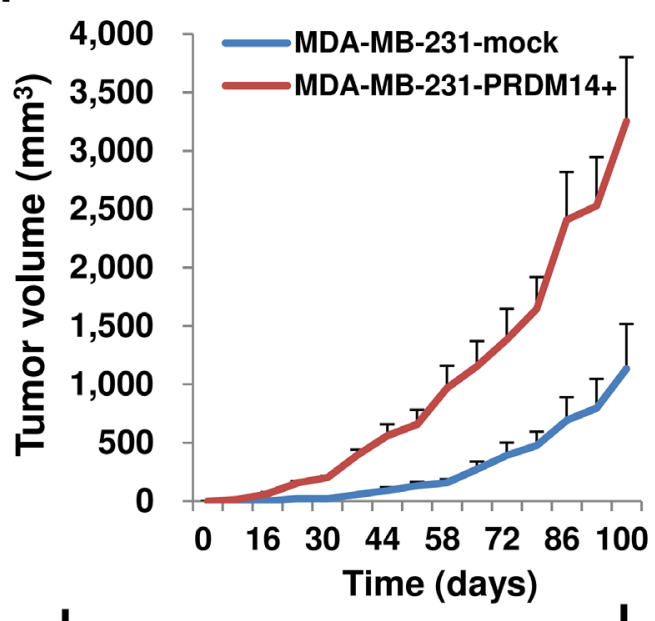

G

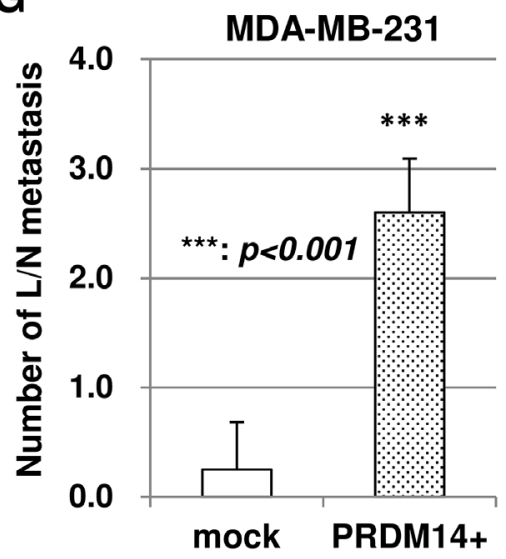

J
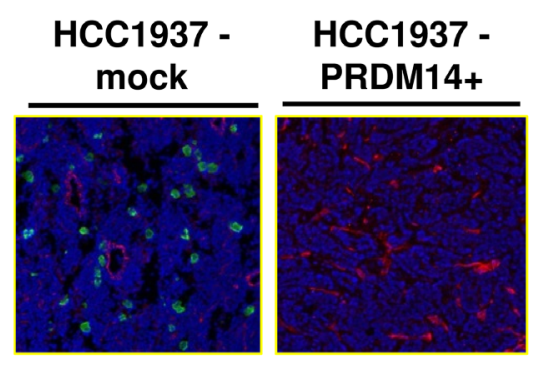

Anti Cleaved Caspase- $3 \rightarrow$ Apoptotic cells Anti CD31 $\rightarrow$ Blood vessel endothelial marker
BBC-4 (TNBC)

Nonadherent cells

PRDM14 scramble

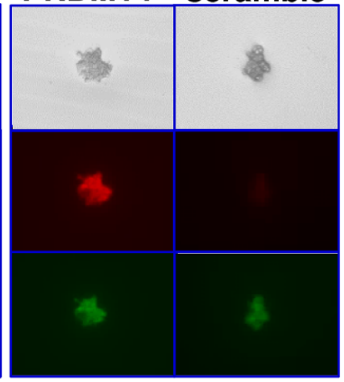

PRDM14

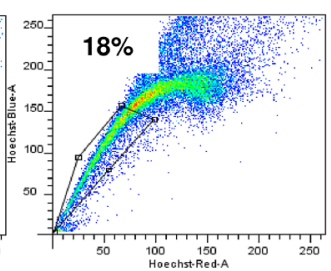

MDA-MB-231
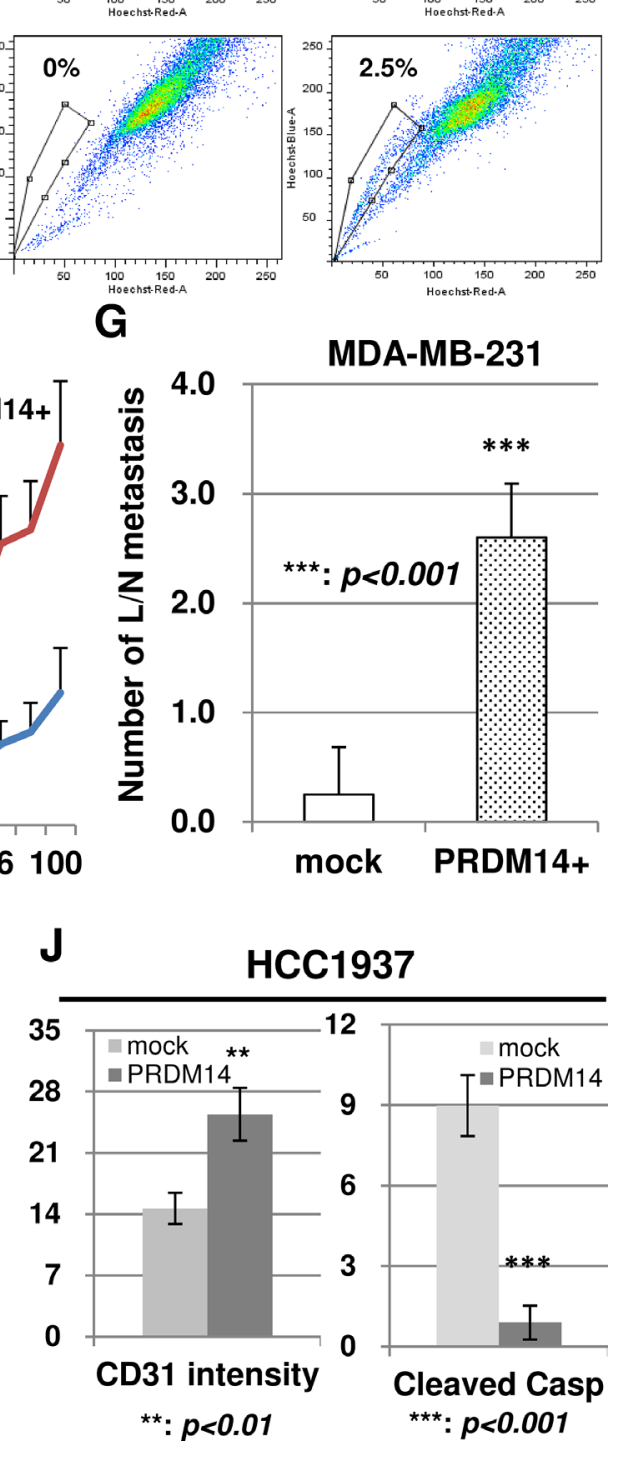
metastasis Ant CDJ1 $\rightarrow$ Blood vessel endothelial marker 
Figure 2: PRDM14 is required for the stemness phenotype of breast cancers. (A) Results of a tumorsphere assay. Representative images showing increased sizes or numbers of tumorspheres after 14 days in culture. (B) Stemness-related markers (Oct3/4, SSEA1, and SSEA4) in tumorspheres formed by PRDM14-transfected HCC1937 cells. (C) PRDM14 mRNA expression in viable cells in tumorspheres (non-adherent cells) and monolayers of primary breast cancer cells, analyzed using SmartFlare PRDM14 (Cy5) or control (Cy3) probes. (D) Effects of PRDM14 on the side-population fractions of PRDM14-transfected breast cancer cell lines (MCF7 and HCC1937). Reserpine, which blocks ABC transporters, was added as a negative control. (E) PRDM14-transfected MDA-MB-231 cells were injected into the mammary fat pad of nude mice. Images of the mice at day 100 after tumor initiation are shown. Orthografted tumors are circled with dotted red lines and lymph node metastases with dotted blue lines. (F) Tumor volumes determined externally using calipers of mice engrafted with PRDM14-transfected MDA-MB-231 cells ( $n=10$ for each group). (G) Number of lymph node metastases in mice engrafted with PRDM14-transfected MDA-MB-231 cells at day 100 after tumor initiation ( $n=10$ for each group). (H) Haematoxylin and eosin (H\&E) staining of lungs and lymph nodes after injection of MDA-MB231-PRDM14+ cells at day 100 after tumor initiation. (I) Microvessel density and apoptosis was measured in frozen tumor sections by immunohistochemical analyses of CD31 and cleaved caspase-3 at day 86 after tumor initiation from mice engrafted with PRDM14-transfected HCC1937 cells in the mammary fat pad. (J) Microvessel density and cleaved caspase-3-positive cells in frozen tumor tissues at day 86 from mice engrafted with PRDM14-transfected HCC1937 cells in the mammary fat pad $(n=16)$. All data are expressed as mean \pm SD.

$(A B C C 3, A B C G 2$, and $E G F R)$, tumor metastasis (CD44, EPHB2, ETV4, IL-18, MMP3, and MMP13), epithelialmesenchymal transition (EMT; Caveolin-2, FGFBP1, integrin alpha 5, and SERPINE1), angiogenesis (CTGF, Fibronectin 1, ID1, IL1B, and ILG), and included stem cell transcription factors (HOXA7, KLF4, PCNA, POU5F1, SOX9, and STAT3) (data not shown).

PRDM14-transfected breast cancer cell lines also exhibited increased expression of oncogenic microRNAs (miRNAs) (miR-101, miR-155, miR-21, miR-221, and miR-23a) and decreased expression of tumor suppressor miRNAs (miR-128a, miR-200a/b, and miR-520f) (Supplementary Table 2).

Silencing PRDM14 reduced the expression of miRNAs upregulated in breast cancer tissues (e.g. miR106a, miR-149, miR-18a, miR-221, miR-222, miR224, miR-23a, miR-24, miR-27a/b, and miR-493) and increased expression of those that were downregulated (e.g. miR-15a, miR-150, miR-183, and miR-203). miR$34 \mathrm{a}$, which is normally expressed at low levels by CSCs [28, 29], was elevated in PRDM14-knockdown (KD) cells (Supplementary Table 2).

qRT-PCR array analyses further detected differential expression of miRNA target genes, notably NOTCH1, $A B C G 2$, and $Z E B 1$ (data available upon request).

\section{Epigenetic regulation of gene expression by PRDM14}

DNA methylation of tumor suppressor genes is a critical step in tumor initiation and progression. Prdm14 has previously been shown to repress DNA methylation in ES cells and primordial germ cells to promote naive pluripotency and germline fate [5]. Therefore, we investigated whether PRDM14 also inhibits DNA methylation in tumorigenic and non-tumorigenic breast cells to promote cancer growth.

We profiled the methylation of 94 tumor suppressor gene promoters that exhibited aberrant DNA methylation in breast cancer tissues using EpiTect Methyl II PCR Array Human Breast Cancer. MDA-MB-231 cells stably expressing PRDM14 showed higher promoter methylation of tumor suppressor genes compared to control cells.
Specifically, we detected increased methylation of the promoters of BMP6, CDH1, EPB4IL3, ESR1, ID4, MUC2, PDLIM4, PER2, PYCARD, RARB, and TGFBI genes. MCF-10A cells stably expressing PRDM14 exhibited higher promoter methylation of the HS3ST3B1 gene compared to control cells. In contrast, HCC1937 and MCF7 cells stably expressing PRDM14 showed little change $(<15 \%)$ in promoter methylation (Table 2$)$.

PRDM14-KD in HCC1937 cells with shRNA decreased promoter methylation of tumor suppressor genes (CADM1, CCNA1, HS3ST3B1, CXCR12, KLK10, LOX, PGR, PLGAL1, PROX1, PTGS2, PYCARD, SLC5A8, TGFBI, WIF1, and ZMYND10) but increased that of oncogenes (CTSZ, RARRES1, TNFRSF10D, and WT1). High levels of RARRES1 in clinical breast cancer samples are correlated with a more aggressive phenotype (by Ki67 positivity and overall grade) and poor patient outcome [30].

Genome-wide analysis of gene promoters with high $\mathrm{CpG}$ density revealed 2.7- and 5.8-fold increases in hyper- compared to hypomethylated regions in PRDM14-transfected MDA-MB-231 and MCF-10A cells, respectively (Supplementary Table 3 ). In contrast, PRDM14-KD induced similar numbers of hyper- and hypomethylated regions in MCF7 and HCC1937 cells (Supplementary Table 3). Genes with hyper- or hypomethylated regions were associated with metabolic and developmental processes and regulation of gene expression (Supplementary Figure 2C).

Taken together, these results demonstrate that PRDM14 represses promoter methylation of protooncogene and stemness gene promoters in PRDM14overexpressing breast cancer cells (MCF7 and HCC1937), as it does in ES and primordial germ cells. In addition, PRDM14 enhanced DNA methylation of tumor suppressor genes in all analyzed cell lines, regardless of native PRDM14 expression levels. When the results of genomewide methylation analyses were compared with those for downregulated genes using expression profiling data in PRDM14-expressing cells, we found that PRDM14 induced DNA methylation of the promoters of downregulated genes in PRDM14-expressing MDA-MB-231 cells. 
Table 2: Methylation status of promoter regions of breast cancer-related genes

\begin{tabular}{|c|c|c|c|c|c|}
\hline \multirow{3}{*}{ Gene } & \multicolumn{4}{|c|}{ PRDM14 transfectant $※$} & \multirow{2}{*}{$\begin{array}{l}\% \text { Change in DNA } \\
\text { methylation }\end{array}$} \\
\hline & \multicolumn{2}{|c|}{ MDA-MB-231 } & \multicolumn{2}{|c|}{ MCF-10A } & \\
\hline & mock & PRDM14 & mock & PRDM14 & Hypermethylation \\
\hline BMP6 & 29.7 & 70.4 & & & $90 \sim 100$ \\
\hline CDH1 & 69.6 & 90.8 & & & $80 \sim 90$ \\
\hline EPB41L3 & 73.3 & 95.9 & & & $70 \sim 80$ \\
\hline ESR1 & 66.7 & 82.3 & & & $60 \sim 70$ \\
\hline GADD45A & & & 20.0 & 0.6 & $50 \sim 60$ \\
\hline HS3ST3B1 & & & 0.1 & 35.7 & $40 \sim 50$ \\
\hline ID4 & 20.0 & 89.1 & & & $30 \sim 40$ \\
\hline MUC2 & 5.6 & 85.9 & & & $20 \sim 30$ \\
\hline PDLIM4 & 29.8 & 67.0 & & & $10 \sim 20$ \\
\hline PER2 & 0.8 & 53.3 & & & $0 \sim 10$ \\
\hline PROX1 & 67.3 & 49.9 & & & $0 \sim-10$ \\
\hline PYCARD & 0.0 & 58.9 & & & $-10 \sim-20$ \\
\hline RARB & 11.7 & 69.9 & & & $-20 \sim-40$ \\
\hline SYK & 93.3 & 62.4 & & & $-40 \sim-60$ \\
\hline TGFBI & 40.6 & 95.6 & & & $-60 \sim-80$ \\
\hline \multicolumn{5}{|c|}{ PRDM14 knockdown by shRNA } & $-80 \sim-90$ \\
\hline \multirow{2}{*}{ Gene } & $\mathrm{HCC}$ & 7 cell & & cell & $-90 \sim-100$ \\
\hline & \multicolumn{4}{|c|}{ compared with control (scrambled) } & Hypomethylation \\
\hline CADM1 & & -99.6 & & & \\
\hline CCNA1 & & -75.0 & & & \\
\hline CTSZ & & 98.9 & & & \\
\hline CXCL12 & & -24.2 & & -10.6 & \\
\hline HS3ST3B1 & & -81.6 & & & \\
\hline KLK10 & & -75.3 & & & \\
\hline LOX & & -100.0 & & & \\
\hline PGR & & -98.1 & & & \\
\hline PLAGL1 & & -35.0 & & & \\
\hline PROX1 & & -99.0 & & & \\
\hline PTGS2 & & -62.6 & & & \\
\hline PYCARD & & -90.9 & & & \\
\hline RARRES1 & & 99.8 & & & \\
\hline SFRP1 & & & & -10.9 & \\
\hline SLC5A8 & & -99.3 & & & \\
\hline TGFBI & & -77.8 & & & \\
\hline TNFRSF10D & & 98.8 & & & \\
\hline WIF1 & & -20.8 & & & \\
\hline WT1 & & 99.9 & & & \\
\hline ZMYND10 & & -24.5 & & & \\
\hline
\end{tabular}

※ HCC1937 cells: change in promoter methylation under $10 \%$

※ MCF7 cells: change in promoter methylation under $10 \%$ 
To determine whether histone modifications required for pluripotency in ES cells are correlated with PRDM14 binding in tumor cells, we performed chromatin immunoprecipitation (ChIP)-sequencing analyses for RNA Pol II, H3K4me3, and H3K27me3 using tagged PRDM14 overexpressed in tumor cells. PRDM14-binding regions were occupied mainly by H3K4me3 and RNA Pol II (Figure 3A). Bivalent chromatin harboring both $\mathrm{H} 3 \mathrm{~K} 4 \mathrm{me} 3$ and H3K27me3 were detected at distinct PRDM14-occupied loci. Other $\mathrm{H} 3 \mathrm{~K} 4 \mathrm{me} 3$ peaks were detected near certain bivalent regions (Figure 3A, Supplementary Figure 2D, 2E).

Bivalent marks are common in undifferentiated cells, with one mark typically being lost during differentiation. Genes with bivalent chromatin occupied by PRDM14 were associated with cell proliferation, migration, and stemness (Supplementary Figure 2D, 2E; Supplementary Table 4). Of 286 bivalent chromatin sites occupied by PRDM14, PRDM14-KD caused 132 to switch to $\mathrm{H} 3 \mathrm{~K} 4 \mathrm{me} 3$ and 8 to $\mathrm{H} 3 \mathrm{~K} 27 \mathrm{me} 3$ monovalent sites in HCC1937 cells.

Using the MEME suite [31], the PRDM14-occupied consensus sequence (5'- GGTCTCTAA -3') was identified as previously reported $[5,32]$ (data not shown). Furthermore, PRDM14-binding peaks (false discovery rate $<0.05$ ) were mainly distributed within $100 \mathrm{~kb}$ of the TSS in HCC1937 and MDA-MB-231 cells (data not shown). Gene Ontology (GO) analysis revealed significant enrichment of PRDM14occupied genes important for development, metabolic processes, transport, protein modification, differentiation, cell signaling, and cell adhesion (Figure 3B).

In PRDM14-transfected MDA-MB-231 cells, PRDM14 co-occupied half of the hypermethylated $\mathrm{CpG}$ sites associated with the TSS (Figure 3C). Using the Bivalent Gene Database (BGDB) [33], we found that $86.0 \%$ and $0.7 \%$ of bivalent genes observed in human ES cells corresponded to PRDM14-occupied genes in PRDM14-overexpressing MDA-MB-231 and HCC1937 cells, respectively (Figure 3D).

\section{Effect of inhibiting PRDM14 expression on stem cell phenotype}

Inhibiting PRDM14 mRNA expression in MCF7 and HCC1937 cells using shRNA (Supplementary Figure 2A, $2 \mathrm{~B}$ ) did not affect cell proliferation in vitro (Supplementary Figure 3A). In contrast, three of seven siRNAs (\#2, \#3, and \#5; Supplementary Table 5) inhibited PRDM14 expression in MCF7 and HCC1937 cells (Supplementary Figure 3B). Due to the 3'-UTR sequence length decrease in many siRNA-resistant cancers [34,35], we used sequences specific to the coding region of PRDM14 (\#2 and \#3). These siRNAs inhibited cell proliferation of all breast cancer cell lines tested (MCF-7, MDA-MB-231, and HCC1937) in vitro, and suppressed cell growth in the presence of low concentrations (compared to those typically used in in-vitro studies) of anticancer drugs
[11,36] (Figure 4A). Treating primary cultures of LBC1, LBC-2, and LBC-5 cells with PRDM14 siRNAs also suppressed tumorsphere formation (Figure 4B).

Downregulation of PRDM14 expression reduced side-population fractions (Figure 4C, Supplementary Figure 3C), which were increased in PRDM14overexpressing cells. PRDM14 siRNA-transfection into MCF7, HCC1937, and MDA-MB-231 cells induced apoptosis, which was more pronounced when the cells were exposed to anticancer drugs (Figure 4D, Supplementary Figure 3D).

\section{Effect of silencing PRDM14 on the growth of tumor xenografts}

To determine whether the beneficial effects of PRDM14-KD observed in vitro could be translated in vivo, we examined tumor growth in nude mice engrafted with PRDM14-KD breast cancer cells. To validate this in another type of cancer with upregulation of PRDM14, we analyzed tumor growth in nude mice engrafted with PRDM14-KD pancreatic cancer (PK-1) cells (Supplementary Figure 2B). Tumors formed by KD cell lines were smaller than those induced by control cells (Figure 4E-4H). Transfecting tumors with PRDM14 abrogated the smaller tumors formed by PRDM14KD HCC1937 cells (Supplementary Figure 3G, 3H). Furthermore, inhibiting PRDM14 expression prevented HCC1937 cells from reverting to a stem-like CD44 ${ }^{+} \mathrm{CK}^{+}$ phenotype (Figure 4I, Supplementary Figure 3E, 3F). Mucus production was prominent in tumors formed by shRNA\#3-transfected PK-1 cells (Figure 4H). Similarly, tumors formed by PRDM14-KD PK-1 cells were differentiated and consisted of squamous or glandular epithelium with mucus production. In contrast, control PK-1 cells formed tumors with poorly differentiated PDX1-expressing cells (Figure 4H, 4J), reminiscent of the early stages of pancreatic tissue development [37].

\section{In vivo model for therapy using a PRDM14- specific siRNA}

We examined the effect of PRDM14-siRNA administration on tumor growth in vivo. We orthotopically grafted wild-type HCC1937 cells into nude mice and directly injected tumors with PRDM14-siRNA mixed with polyethyleneimine (PEI). PRDM14-specific siRNA alone decreased tumor size, an effect that was enhanced with the addition of anticancer drugs (Figure 5A, 5B). Although DOX treatment induced therapy-associated deaths in all groups, this was not observed in DOC-treated mice.

To investigate the effect of PRDM14 siRNA on metastatic growth, MDA-MB-231 cells were injected into mice via the tail vein. After approximately 45 days, pulmonary metastases formed in the controls but not in PRDM14 siRNA-treated mice (Figure 5C, 5D). 

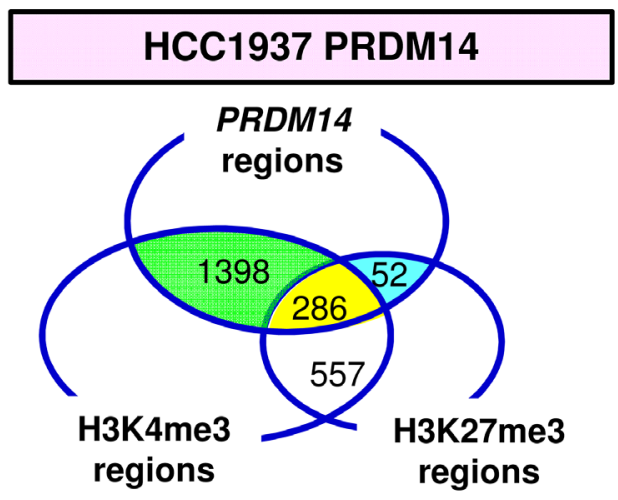

MDA-MB-231 PRDM14

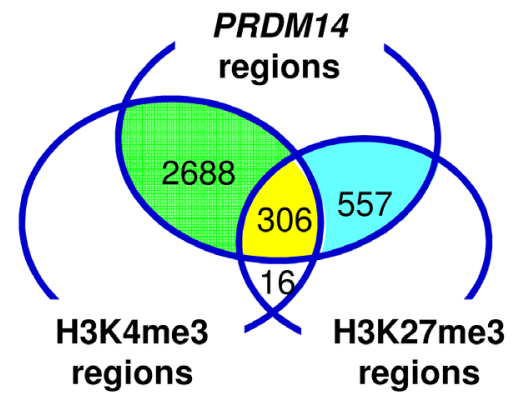

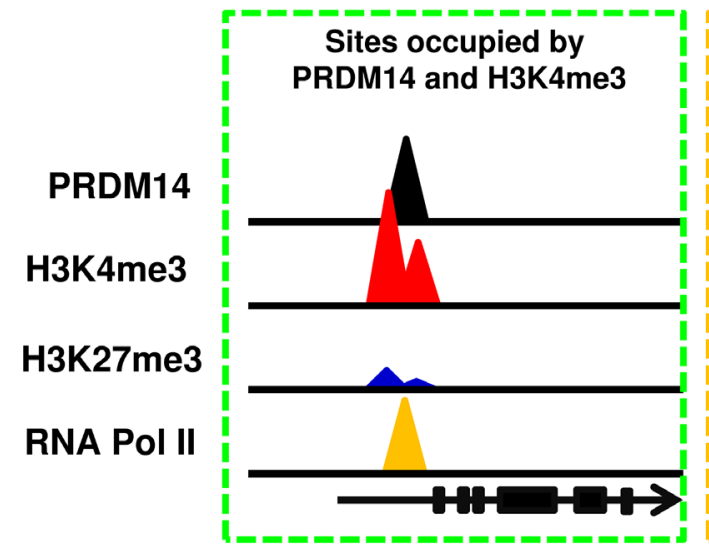

B

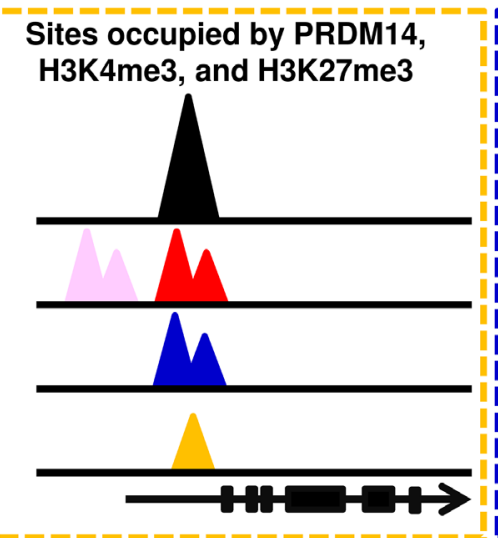

Sites occupied by PRDM14 and H3K27me3

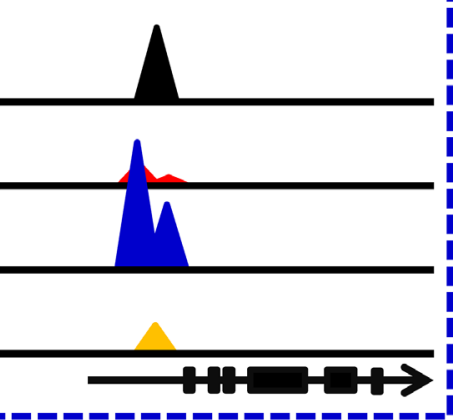

HCC1937 (Coverage >10)

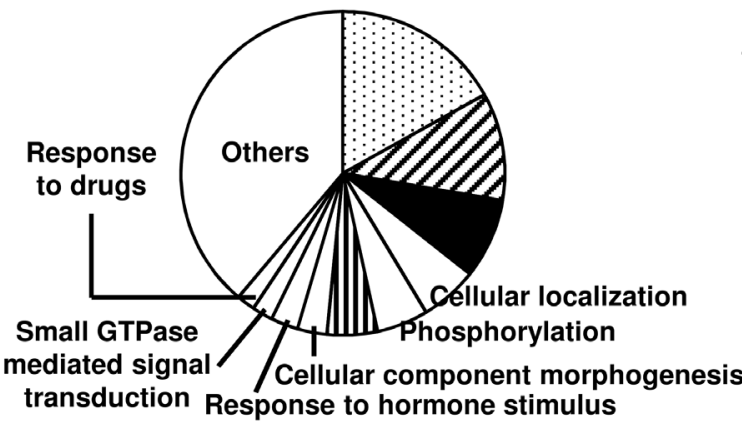

mediated signal Cellular component morphogenesis

transduction Response to hormone stimulus

\section{MDA-MB-231 (Coverage >20)}

Regulation of kinase activity Regulation of
transferase actiuity Others Develepmental

Cell migration Cell differentiatiog

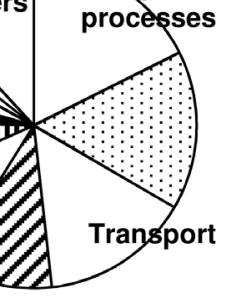

Transport
Protein metabolic process
Cell signaling transduction
Q Protein modification process
III Cell adhesion

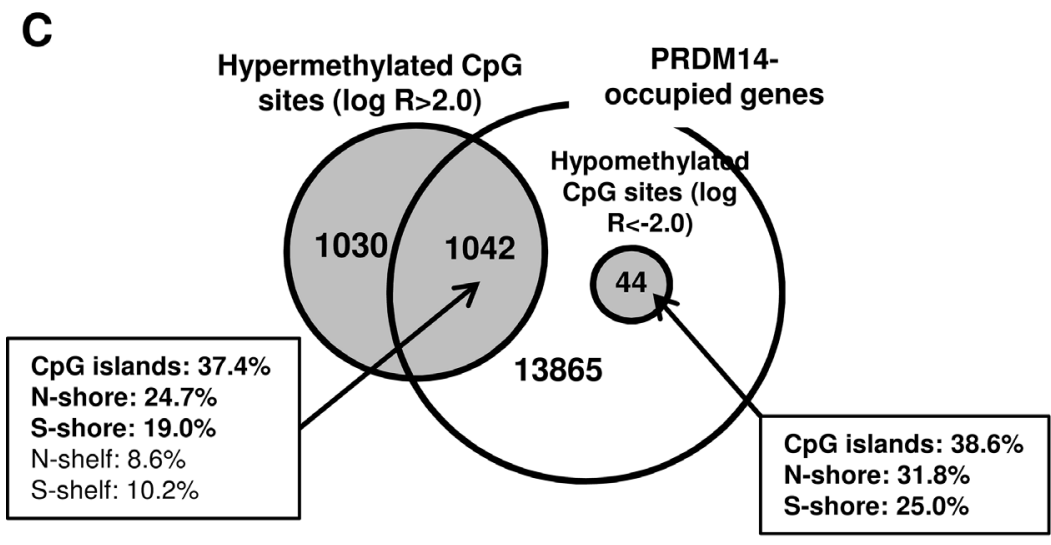

D

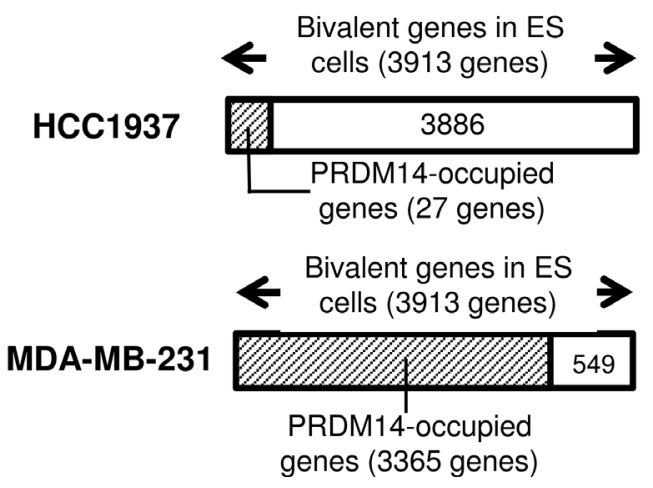


Figure 3: PRDM14 induces epigenetic changes. (A) Relationships among sites occupied by PRDM14, H3K4me3, and H3K27me3 were determined using ChIP-sequencing (depth of coverage [75th percentile] > 10) in PRDM14-transfected HCC1937 and MDA-MB-231 cells. The schema of histone modification patterns of the genomes occupied by PRDM14 for those cells is shown. (B) Gene Ontology (GO) annotations of PRDM14-occupied genes in PRDM14-transfected HCC1937 and MDA-MB-231 cells. EASE Score, modified Fisher exact $P$ value $<0.03$. (C) Relationship between PRDM14-occupied genes and CpG sites with DNA methylation changes. Genome-wide analysis of PRDM14-transfected MDA-MB-231 cells. Percentages of promoter CpG islands and surrounding regions; i.e., shores (2-kb flanking the CpG islands) and shelves (2-kb flanking the shores). (D) PRDM14-occupied genes in PRDM14-transfected breast cancer cells compared with bivalent genes in hES cells.

Chimera RNAi has many advantages over conventional siRNAs in vivo [14-16]. Further, CaP hybrid micelles have been used to efficiently deliver siRNA to tumors via intravenous injection [17]. Therefore, we tested this delivery method for PRDM14 chimera RNAi for cancer treatment. After the orthotopic tumor reached a predetermined size, we injected a chimera RNAi mixed with $\mathrm{CaP}$ hybrid micelles into the tail vein three times per week and/or a low dose of DOC intraperitoneally once each week. PRDM14-specific chimera RNAi alone decreased orthotopically grafted tumor size, which further decreased when the mice were additionally treated with DOC (Figure 5E-5G). Inhibition of PRDM14 expression in the tumor by chimera RNAi was confirmed using qRTPCR and immunohistochemical analyses (Figure 5H, 5I). Apoptotic or necrotic areas in the tumor center were larger in the RNAi therapy group than in the control group (data not shown).

To validate the effects of PRDM14-siRNA treatment, we analyzed Prdm14 knock-out (KO) in MMTV-Wnt-1 transgenic mice, a spontaneous model of murine breast cancer. Prdm14-KO causes sterility in male and female mice due to early germ cell deficiency [4]. Therefore, we generated a conditional Prdm14 allele by introducing loxP sites flanking exon 5, which, together with exon 4, encodes the PR-domain. We crossed Prdm $14^{\text {flox/+ }}$ mice to beta-lactoglobulin promoter (LGB)-cre mice to generate a germline Prdm14 deletion only in the mammary glands. Breast tumor formation was absent in all Prdm14 ${ }^{\text {flox/flox; }}$ LGB-Cre $(n=22)$ and Prdm $14^{\text {flox/flox }}(n=10)$ mice over the course of a 200-day observation period.

To ensure that the anti-tumor effects of PRDM14siRNA treatment were due to PRDM14 inhibition, we generated Prdm14 KO; Wnt-1 transgenic mice. Prdm14 is indirectly induced by Wnt/beta-catenin signaling [18,19]. Moreover, MMTV-Wnt-1 transgenic mice develop mammary neoplasia due to ectopic Wnt-1 production. Wnt-1 transgenic mice were used to generate Prdm14 KO; Wnt-1 mice by mating Prdm 14+/-; LGB-cre; Wnt-1 mice with Prdm14 $4^{\text {flox/flox }}$ mice. We observed breast tumor formation in both Prdm14-KO; Wnt-1 and Prdm14 $4^{\text {flox/ }}$ flox; Wnt-1 transgenic mice after parturition and lactation (Supplementary Figure 4A). However, observational follow-up revealed that the age range of disease onset was 20-180 days (median disease-free survival time $=49$

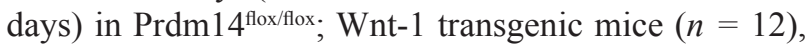
compared to 21-138 days (median disease-free survival time $=103$ days) in Prdm14-KO; Wnt-1 transgenic mice $(n=10)$. Therefore, Prdm14 $14^{\text {flox/flox}} ;$ Wnt-1 transgenic mice have a reduced disease-free survival period compared to Prdm14-KO; Wnt-1 mice ( $p=0.045$, Gehan-BreslowWilcoxon test) (Figure 5J). Breast tumors formed in PRDM14-KO; Wnt-1 transgenic mice exhibited cysts with mucus production and fibrotic lesions, which were not observed in Prdm14 $4^{\text {flox/flox; }}$ Wnt-1 transgenic mice (Supplementary Figure 4B, 4C). Moreover, Prdm14 $4^{\text {flox/ }}$ flox; Wnt-1 transgenic mice displayed a greater number of spontaneous lung metastases than PRDM14-KO; Wnt-1 transgenic mice (Supplementary Figure 4D-4F).

\section{DISCUSSION}

The present study examined PRDM14 expression in cancer tissues and its effect on CSC formation by investigating whether PRDM14 induces biological properties consistent with the CSC phenotype and influences the epigenetic state of cancer cells. We showed that, in addition to the previously reported overexpression of PRDM14 in lung cancer, testicular tumors, and lymphoma, PRDM14 is also elevated in esophagus, pancreas, ovary, kidney, and bladder cancers, and is associated with poor survival of patients with breast cancer. PRDM14 conferred stem cell-like phenotypes to cancer cells and regulated the expression of genes involved in cancer stemness, metastasis, and chemoresistance. PRDM14 reduced the DNA methylation of proto-oncogene and stemness gene promoters but enhanced methylation of tumor suppressor genes in cancer cells. Administration of PRDM14 siRNA using $\mathrm{CaP}$ hybrid micelles reduced tumor size and metastases in vivo. Conditional loss of Prdm14 function also improved survival in MMTV-Wnt-1 transgenic mice, a spontaneous model of murine breast cancer containing CSC fractions.

Although PRDM14 expression was associated with poor survival of breast cancer patients, expression was not correlated with breast cancer stage. Assuming that PRDM14 was expressed by CSCs in these tumor tissues and was involved in aberrant epigenetic changes in cancer, that PRDM14 expression was not correlated to disease stage may be explained by the heterogeneous size of the CSC population in tumors $[38,39]$ and epigenetic changes observed in the earliest events of cancer initiation.

We showed that PRDM14 confers CSC phenotypeassociated biological properties, including drug resistance, increase in the side-population fraction, 
A
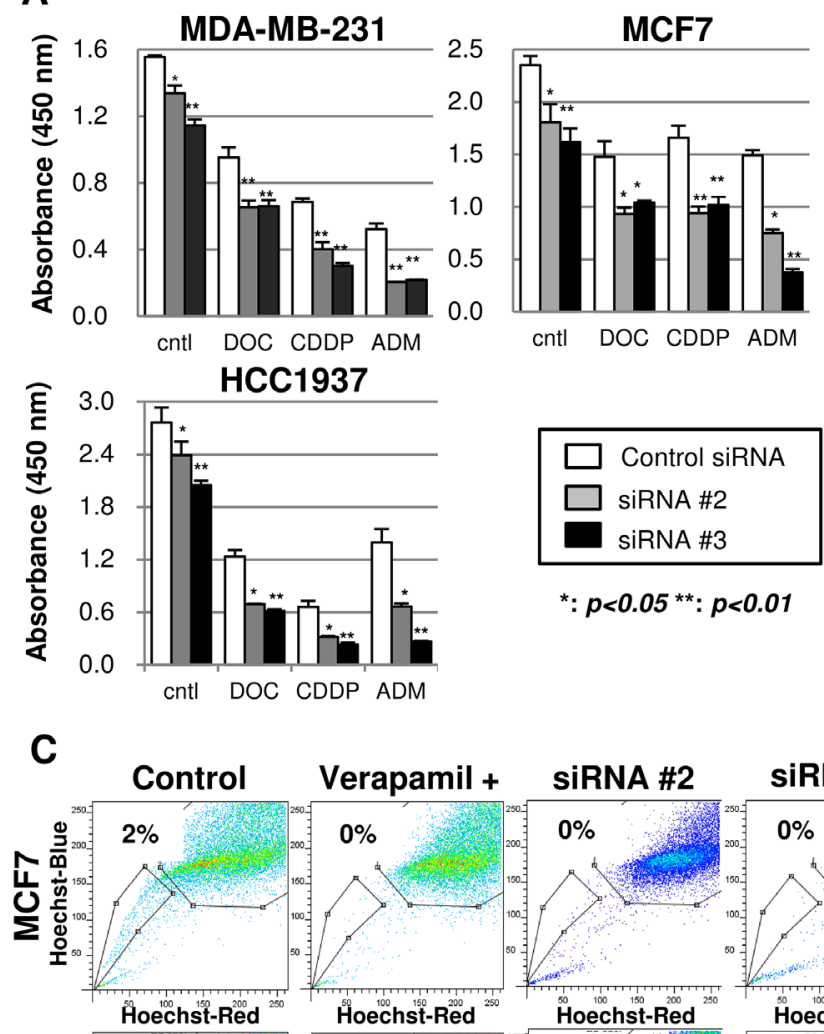

${ }^{*}: p<0.05^{* *}: p<0.01$
B
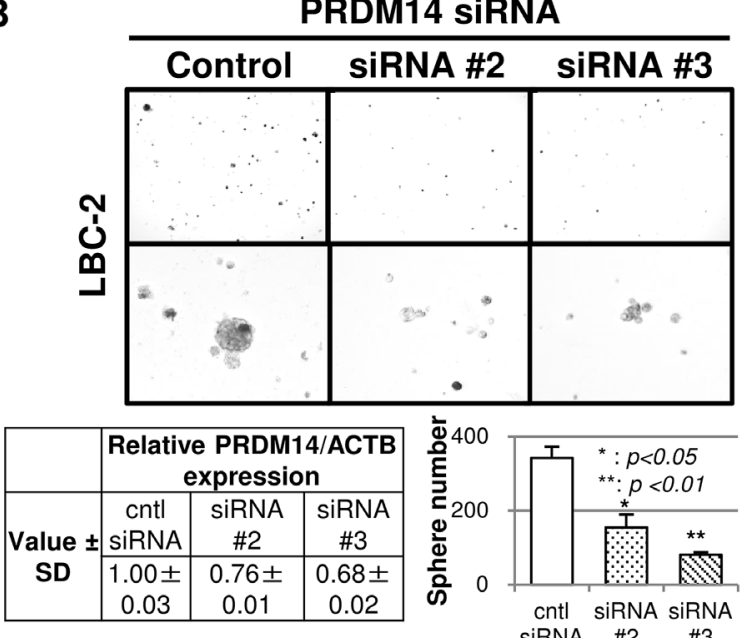

D
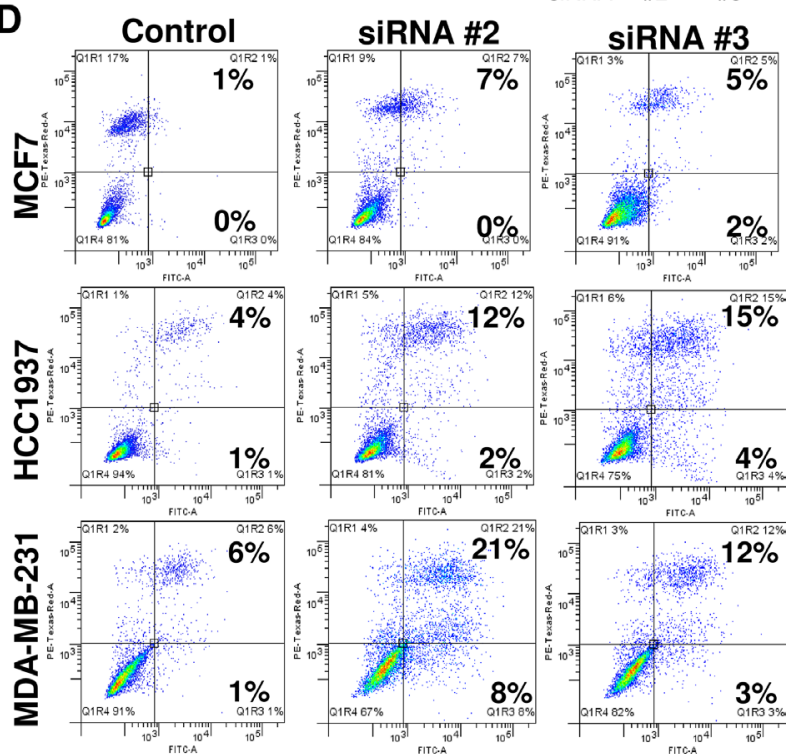

H

PK-1
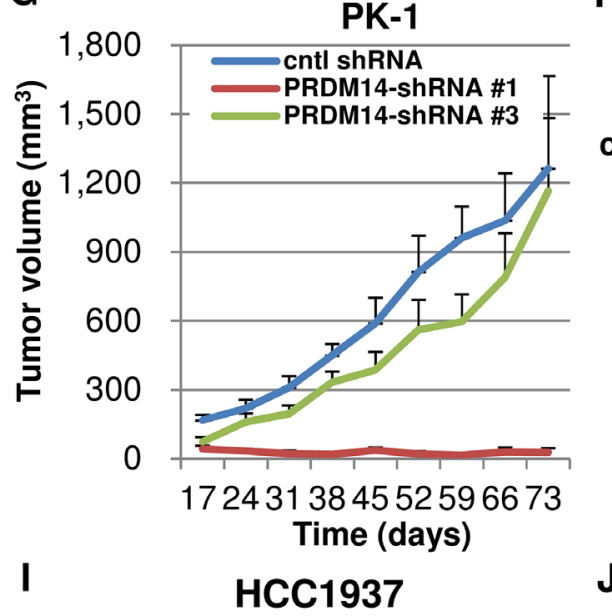

J

PK-1 cntl ShRNA

PK-1 shRNA \#1

PK-1 shRNA \#3 PK-1

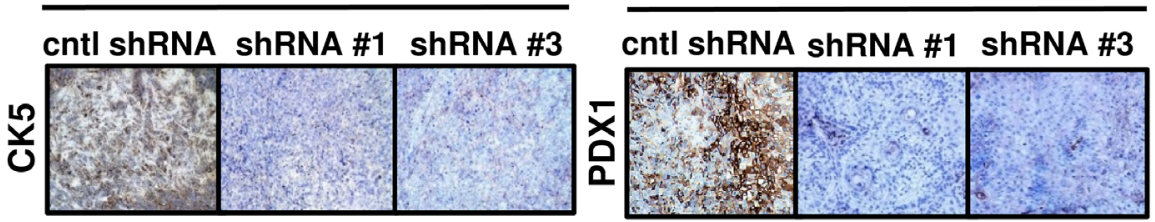


Figure 4: Silencing PRDM14 eliminates the stem cell phenotype and tumor growth. (A) Proliferation of PRDM14 siRNAtransfected cancer cells cultured in the presence or absence of the indicated drugs (WST-8 assay) $(n=3)$. Control (scrambled sequence) or PRDM14-specific siRNA (5 nM); DOC, docetaxel (0.5 $\mu \mathrm{M})$; CDDP, cis-diamminedichloroplatinum $(25 \mu \mathrm{M})$; and DOX, doxorubicin (1 $\mu \mathrm{M})$. (B) Tumorsphere formation by breast cancer cells in primary culture treated with control or PRDM14-specific siRNA (5 nM) for 72 h; $10 \times$ and $20 \times$ magnification (upper and bottom rows, respectively). (C) Side-population fraction of control or PRDM14-specific siRNAtransfected cancer cells. Verapamil, which blocks ABC transporters, was added as a negative control. (D) Effects of PRDM14 on apoptosis of PRDM14-specific siRNA-transfected breast cancer cells. Lower and upper right quadrants indicate annexin-positive early apoptotic cells and annexin/propidium iodide-positive late apoptotic cells, respectively. (E) Orthograft tumor growth in mice engrafted with HCC1937 cells stably transfected with control-shRNA (scrambled sequence), PRDM14-shRNA \#1, or PRDM14-shRNA \#3 in the mammary fat pad ( $n=6 /$ group). (F) Images of orthograft tumors from mice engrafted with HCC1937 cells stably transfected with control-shRNA (scrambled sequence), PRDM14-shRNA \#1, or PRDM14-shRNA \#3 in the mammary fat pad ( $n=6$ /group) (day 60). (G) Xenograft tumor growth in nude mice engrafted with PK-1 cells (pancreatic cancer cell line) stably transfected with control-shRNA (scrambled sequence), PRDM14-shRNA \#1, or PRDM14-shRNA \#3 ( $n=6$ /group). (H) H\&E staining of xenograft tumors formed by PK-1 cells transfected with control shRNA, shRNA \#1, or shRNA \#3 at day 73 after tumor initiation; $20 \times$ (cntl shRNA and left panels for shRNA \#1 and \#3) and 40× magnification (right panels for shRNA \#1 and \#3). Scale bar, $300 \mu \mathrm{m}$. (I) CK5 expression in tumors formed by HCC1937 cells transfected with control shRNA, shRNA \#1, or shRNA \#3. 20× magnification. (J) PDX1 expression in tumors formed by PK-1 cells transfected with control shRNA, shRNA\#1, or shRNA \#3. 20× magnification.

rate of tumorsphere formation, and expression of stem cell markers used to identify CSCs [40]. In contrast, silencing PRDM14 decreased CSC phenotype-associated biological properties and prevented breast cancer cells from recovering stemness. These effects were not limited to breast cancer cells, as shown by our findings with PDX1, which is associated with the regulation of the earliest stages of normal pancreatic development and poor prognosis of pancreatic cancer [37]. Thus, PRDM14 is involved in maintenance of the CSC phenotype and inhibition of PRDM14 expression induces cancer cell differentiation.

PRDM14 expression did not promote cancer cell proliferation in 2D culture but enhanced tumor cell proliferation in vivo or in a near-in vivo environment, such as low attachment growth conditions. Interestingly, treatment of breast tumor spheroids, but not monolayers, with chemotherapeutic drugs induces TGF- $\beta 1$ expression, mimicking tumor cell response to treatment in vivo [41]. Further, cancer cells in 3D culture are more similar to clinical tumor cells than cancer cells in 2D culture in terms of gene expression patterns, proliferation phenotypes, and resistance to apoptosis and chemotherapeutic drugs [41-44]. Our results indicate that PRDM14 expression is higher in tumorspheres than in monolayers of cancer cells. Tenascin C, an essential factor in the aggressiveness of pulmonary metastasis of breast cancer, is also more highly expressed in tumorspheres than in monolayer cultures of breast cancer cells [45]. Therefore, PRDM14, like tenascin C, may be required for CSC plasticity and the formation of tumorsphere initiating cells, leading to more aggressive cancer phenotypes.

Our findings also suggest that PRDM14 expression is associated with factors that inhibit immune response. We found that PRDM14 was frequently expressed by $\mathrm{CK}^{+} \mathrm{CK}^{-}{ }^{-}$estrogen receptor-negative breast cancer cells, and that PRDM14 prevented reversal of HCC1937 cells to a stem-like phenotype, suggesting that PRDM14 maintains breast cancer cells in an undifferentiated state. Furthermore, an inverse correlation between PRDM14 expression and lymphocyte infiltration into breast tumors indicates that PRDM14-expressing cancer cells escape immunosurveillance. This finding is supported by previous reports that breast CSCs escape T cell-mediated immunosurveillance. CD44 $4^{\text {high }} / \mathrm{CD} 24^{\text {low/neg }}$ breast CSCs escape NK cell-mediated surveillance [46] and express higher levels of programmed death-ligand 1 (PD-L1), which binds to the PD-1 checkpoint on immune cells [47]. Moreover, breast CSCs secrete TGF- $\beta$, which inhibits antitumor immune responses [48]. Therefore, we speculate that PRDM14 may prevent the detection of breast tumor cells by the immune system to worsen cancer prognosis.

To gain insight into the molecular mechanisms by which PRDM14 enhances the malignant phenotype, we investigated gene expression profiles in cells that differentially expressed PRDM14. PRDM14 regulated the expression of genes and miRNAs involved in cancer cell stemness, metastasis, and drug resistance. Moreover, silencing PRDM14 reduced the expression of CD44, which imparts cancer stemness [49], and STAT3, which is required for growth of $\mathrm{CD}_{4}{ }^{+} \mathrm{CD} 24^{-}$stem cell-like breast cancer cells [50].

PRDM14 contributes to naive pluripotency in ES cells by repressing DNA methylation [5]. We showed that PRDM14 has similar actions in breast cancer cells: PRDM14 was associated with the 'activating' H3K4me3 modification and reduced methylation of protooncogene and stemness gene promoters in breast cancer cells. Additionally, however, PRDM14 induced DNA methylation to repress several tumor suppressor genes in cancer cells, but not ES cells. In contrast, PRDM14 directly represses developmental gene expression in ES cells via the 'repressive' H3K27me3 mark [51].

$\mathrm{H} 3 \mathrm{~K} 4 / \mathrm{K} 27 \mathrm{me} 3$ modifications were found at PRDM14-occupied regions, suggesting that PRDM14 creates a bivalent histone-modification state in the promoter region of target genes. Because polycomb proteins and DNA methyltransferases are aberrantly overexpressed in cancer cells $[52,53]$, PRDM14 might induce DNA methylation in genome areas with bivalent chromatin to readily induce epigenetic changes. In fact, genes with promoter regions that display bivalent 
A

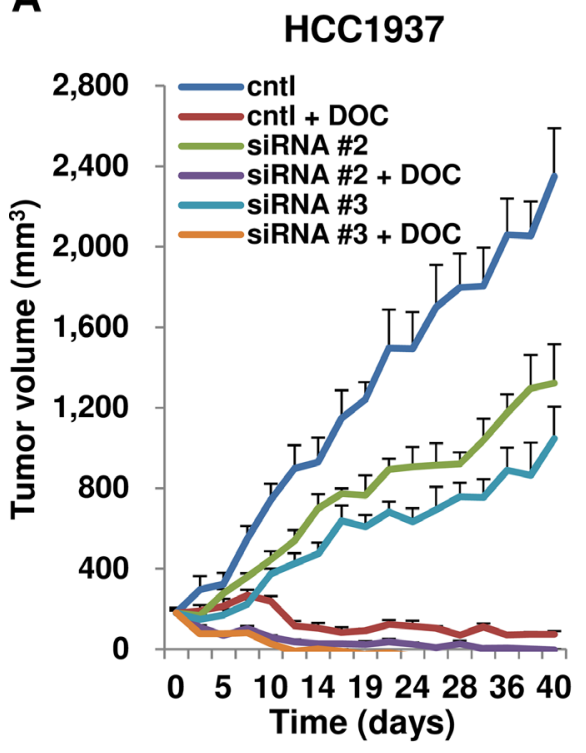

E

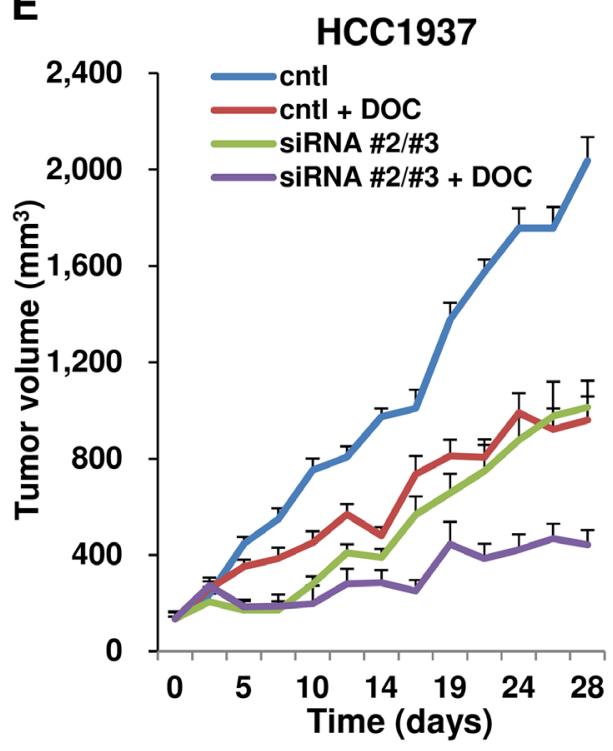

H

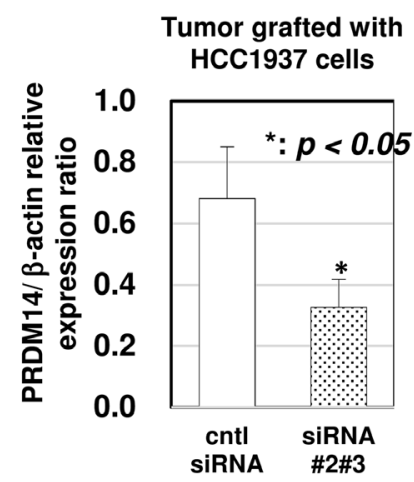

B

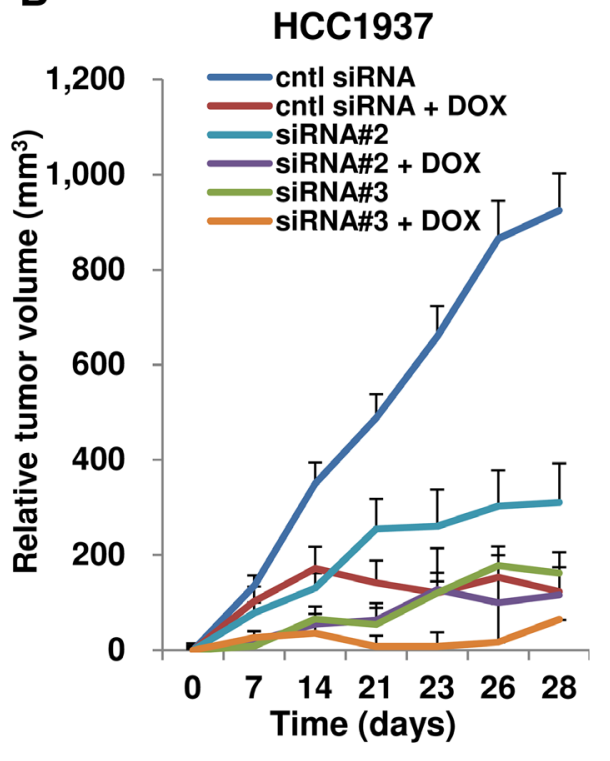

$\mathbf{F}$

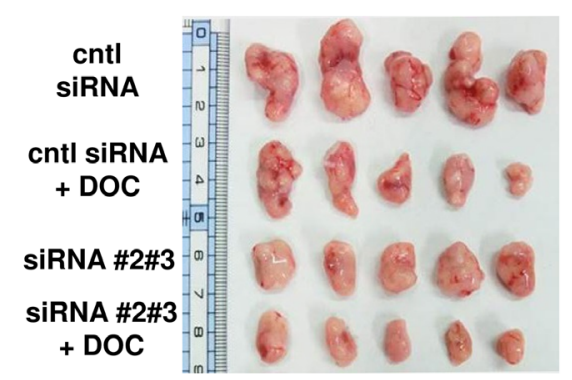

Tumor grafted with $\mathrm{HCC} 1937$ cells

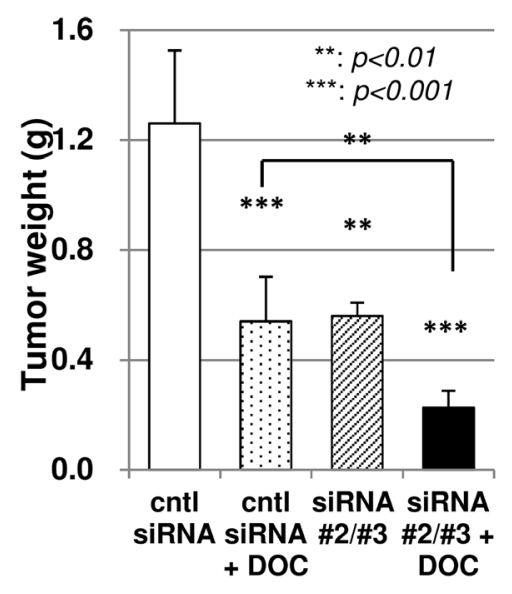

C

D

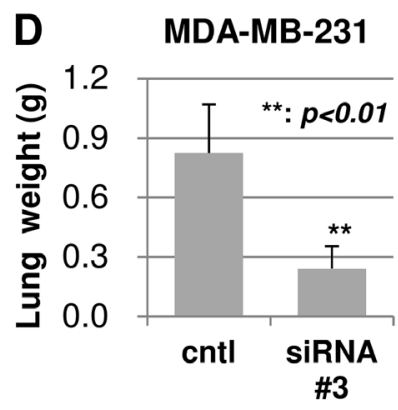

G

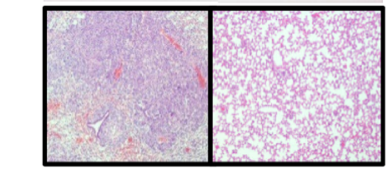
cntl siRNA SiRNA \#3 
Figure 5: PRDM14-specific siRNA reduces the tumorigenicity of breast cancer cells in vivo. (A) Intratumoral injection of the control or PRDM14-specific siRNA/PEI complex with or without docetaxel (DOC) reduces HCC1937 cell tumorigenicity $(n=6 /$ group). (B) Intratumoral injection of the control or PRDM14-specific siRNA/PEI complex with or without doxorubicin (DOX) reduced HCC1937 cell tumorigenicity ( $n=6$ /group). (C) Suppression of lung metastasis in mice injected intravenously with MDA-MB-231 cells treated with PRDM14-specific siRNA. Representative images of lungs and histological lung sections from mice treated with control (left) or PRDM14-specific siRNA (right). H\&E staining; magnification, $\times 10$. (D) Lung weight of mouse model for lung metastatic breast cancer (MDA-MB-231 cells) treated with PRDM14-specific siRNA ( $n=8 /$ group). (E) Intravenous injection (three times per week) of chimeric PRDM14-specific siRNA/CaP hybrid micelles with or without DOC (once per week) reduced the tumorigenicity of HCC1937 cells. Tumor volumes are shown ( $n=8$ /group). (F) Orthografted tumor images treated with chimeric $P R D M 14$-specific siRNA/CaP hybrid micelles with or without DOC at the end-point (day 28). (G) Orthografted tumor weights after chimeric PRDM14-specific siRNA/CaP hybrid micelle treatment with or without DOC (day 28) ( $n=8$ /group). (H) PRDM14 knockdown in orthografted tumors after chimeric PRDM14-specific siRNA/CaP hybrid micelle treatment was estimated using qRT-PCR ( $n=8$ /group). Data are presented as mean $\pm \mathrm{SD}$. (I) Immunohistochemical expression of PRDM14 in an orthografted tumor sample after chimeric control (left) or PRDM14-specific siRNA/ $\mathrm{CaP}$ hybrid micelle treatment (right). Data are presented as mean \pm SD. (J) Kaplan-Meier curve for disease-free survival of conditional Prdm14 knock-out (cKO: Prdm14 flox/flox; LGB-Cre) mice crossed with spontaneous model of murine breast cancer (Wnt-1 transgenic) mice. Breast tumor formation in Prdm14 cKO; Wnt-1 transgenic mice $(n=10$; red line $)$ compared with Prdm $14^{+++}$; Wnt- 1 transgenic mice $(n=$ 12; blue line) after parturition and lactation. Green line indicates disease-free survival of wild type mice and Prdm14 cKO mice. $p=0.045$, Gehan-Breslow-Wilcoxon test.

histone marks in ES cells are methylated in cancer cells [54]. These genes are involved in tumor progression and resistance to anticancer drugs [55]. Since PRDM14 overexpression occurs during the early stages of cancer, PRDM14 may serve as an initial trigger of epigenetic changes in tumors.

Tumor growth in vitro was suppressed by a PRDM14 siRNA but was unaffected by an shRNA construct. Downregulation of Dicer or DROSHA expression is associated with an aggressive cancer phenotype [56, 57]. Downregulating Dicer inhibits the silencing effects of shRNAs but not that of siRNAs [57]. Therefore, siRNA was a better choice for in vivo studies for developing novel cancer therapies.

We also provided proof-of-principle analysis of an in vivo treatment model using $\mathrm{CaP}$ hybrid micelles for intravenous delivery of chimera RNAi to inhibit PRDM14 expression. This treatment caused significant tumor shrinkage and prevented metastasis without any adverse effects. Adjunct treatment with DOC further enhanced tumor shrinkage.

In our expression experiments, PRDM14 mRNA was found in normal ovarian tissue derived from noncancerous parts of cancer tissues. PRDM14 is expressed in putative ovarian stem cells isolated from human adult ovaries [58]. Treatment with anti-PRDM14 therapy by siRNA/CaP hybrid micelles, however, should not affect the expression of PRDM14 mRNA in normal ovarian tissue since this technique specifically accumulates siRNA in targeted cancer tissues by EPR effects. Moreover, our nonclinical tests of PRDM14 siRNA with DDS in rodents and M. fascicularis silenced PRDM14 with no adverse effects, including on ovarian tissue, as determined by pathologic examination.

In summary, PRDM14 conferred resistance to chemotherapy and apoptosis, sphere-forming ability, enhanced vascularization, tumorigenicity and metastasis in vivo on breast cancer cells through a similar system to that employed in ES cells. Our results suggest that PRDM14 serves as an initial trigger for epigenetic changes and hyperdynamic plasticity in tumors via bivalent chromatin domains. Importantly, our work shows that PRDM14 may be an ideal target in many tumor types for eliminating residual cancer cells without adverse effects.

\section{MATERIALS AND METHODS}

\section{Expression analyses and samples}

We analyzed the $\mathrm{RT}^{2}$ Profiler PCR Arrays (QIAGEN, Hilden, Germany) and the Cancer Survey cDNA array or Breast Cancer cDNA array (OriGene, Rockville, MD, USA) to detect mRNA using qRTPCR with CYBR Green and a ViiA7 System (Life Technologies, Carlsbad, CA, USA). Paraffin sections were generated from formalin-fixed tissues of 213 Japanese patients (Table 1). The Genome Ethics Committee of the University of Tokyo, and the Ethics Committee of the Kanagawa Cancer Research \& Information Association (KCRIA) reviewed and approved all procedures. All samples were collected with informed consent according to the Internal Review and Ethics Boards of the Kanagawa Cancer Center (Kanagawa, Japan). PRDM14 expression and localization were determined using tissue microarrays that included tumor and normal tissues. Additional details are provided in the Supplementary Methods.

\section{Cell lines and cell culture}

All cell lines were obtained from the American Type Culture Collection (Manassas, VA, USA) or RIKEN BRC (Tsukuba-shi, Ibaraki, Japan). The cell lines were actively passaged within 6 months of receipt. Cell lines were cultured in Dulbecco's Modified Eagle Medium (DMEM) (MDA-MB-231 and MCF7 cells) or Roswell 
Park Memorial Institute (RPMI) 1640 culture media (HCC1937 cells) with 10\% fetal bovine serum (FBS) in $5 \% \mathrm{CO} 2$ at $37^{\circ} \mathrm{C}$.

Primary cultures from the initial site of invasive breast cancers were established from patients with luminal-type (LBC-1, LBC-2, and LBC-5) and basaltype (BBC-4) cancers. Tumor samples were washed with phosphate-buffered saline (PBS) and homogenized using Liberase TL Research Grade (Sigma-Aldrich, St. Louis, MO, USA). Cells were cultured in Ultra-Low attachment 6-well plates (Corning, NY, USA). Epidermal growth factor (EGF) and basic fibroblast growth factor (b-FGF; 20 $\mathrm{ng} / \mathrm{mL}$ each) were added to $50 \mathrm{~mL}$ DMEM/F12 medium (Life Technologies). After the addition of $0.5 \mathrm{~mL} \mathrm{~B} 27$ supplement (Life Technologies), the cells were cultured at $37^{\circ} \mathrm{C}$ in $5 \% \mathrm{CO}_{2}$. Further details are provided in the Supplementary Methods.

\section{Lentiviral transduction and siRNA transfection}

Cell lines were engineered to stably express or knock down PRDM14 through lentiviral-mediated gene delivery. Lentivirus was produced by co-transfection of 293T cells with a lentiviral construct (GeneCopoeia, Rockville, MD, USA) and lentiviral packaging plasmids. Lentiviral particles were collected $48 \mathrm{~h}$ after transfection and filtered through a $0.45-\mu \mathrm{m}$ filter before the addition of Polybrene $(10 \mu \mathrm{g} / \mathrm{mL})$. Target cells $\left(5 \times 10^{4}\right.$ cells $)$ were cultured with medium containing lentiviral particles for 48 hours before addition of puromycin $(1 \mu \mathrm{g} / \mathrm{mL})$ for selection. After selection, transfection was confirmed by mRNA and protein expression analyses.

Cancer cells were transfected with PRDM14specific siRNA (5 nM) using the RNAiMAX Reagent (Life Technologies) according to the manufacturer's protocol. The culture medium was replaced after $24 \mathrm{~h}$. In vitro assays were performed $72 \mathrm{~h}$ later. For combined treatments, cis-diamminedichloroplatinum (CDDP; 25 $\mu \mathrm{M}$ ), doxorubicin (DOX; $1 \mu \mathrm{M}$ ), or docetaxel (DOC; 0.5 $\mu \mathrm{M}$ ) was also added to the medium $48 \mathrm{~h}$ later.

\section{Analysis of cancer cell side-population fractions}

Cells were cultured at $37^{\circ} \mathrm{C}$ in DMEM supplemented with $5 \%$ FBS. Cells were suspended in $4 \mathrm{~mL}$ of $5 \%$ FBSDMEM $\left(1 \times 10^{6}\right.$ cells $\left./ \mathrm{mL}\right)$. Reserpine $(20 \mu \mathrm{M})$ was added to $1 \mathrm{~mL}$ aliquots of the cell suspensions. Cells were then incubated for $10 \mathrm{~min}$ at $37^{\circ} \mathrm{C}$. Hoechst 33342 dye $(5 \mu \mathrm{M})$ was added to both cell populations. The cells were incubated with shaking for $90 \mathrm{~min}$ at $37^{\circ} \mathrm{C}$, immediately cooled on ice, centrifuged for $5 \mathrm{~min}$ at $300 \times \mathrm{g}, 4^{\circ} \mathrm{C}$, and resuspended in cooled $1 \times \mathrm{PBS}-5 \% \mathrm{FBS}$ solution. This procedure was repeated three times and propidium iodide was added. Analysis was performed using a FACSAria (BD Biosciences, San Jose, CA, USA). Data were analyzed using FlowLogic software (Affymetrics, Santa Clara, CA, USA).

\section{miRNA expression and DNA methylation profile analyses}

miRNA analyses were performed using the TaqMan Array MicroRNA Card (Life Technologies) in accordance with the manufacturer's protocol. The results were analyzed using ExpressionSuite Software v1.0 (Life Technologies).

Gene methylation was evaluated by EpiTect Methyl II PCR Arrays (QIAGEN), as per the manufacturer's instructions, and Human Breast Cancer Complete Panel (QIAGEN). The Infinium Methylation 450K assay (Illumina Inc., CA, USA) was performed according to Illumina's standard protocol. Details are provided in the Supplementary Methods.

\section{ChIP sequencing}

Breast cancer cells were transfected with a HaloTagPRDM14 lentivirus expression vector (GeneCopoeia). PRDM14-bound genomic DNA fragments were immunoprecipitated from cell lysates with HaloLink Resin (Promega, Madison, WI, USA) and immunoprecipitated with anti-H3K4me3, anti-H3K27me3, and anti-RNAPII antibodies.

DNA fragments were processed according to the Ion PGM ChIP-sequencing protocol (Life Technologies). Ion 318 chips (Life Technologies) were used for the analysis. ChIP-DNA fragment genome mapping was performed using NextGENe software (SoftGenetics, State College, PA, USA). Details are provided in the Supplementary Methods.

\section{In vivo models}

Tumor cells $\left(1 \times 10^{6}\right.$ cells/mouse $)$ were inoculated into the mammary fat pads of female nude mice (CLEA Japan, Tokyo, Japan). Tumor length and width were measured using a caliper. After tumors exceeded $100 \mathrm{~mm}^{3}$ in volume, siRNA and/or anticancer drug treatments were initiated. siRNA (1 mg/kg) and in vivo-jetPEI (Polyplus Transfection, Illkirch, France) were injected directly into the tumors three times a week. DOX $(1 \mathrm{mg} / \mathrm{kg})$ or DOC $(10 \mathrm{mg} / \mathrm{kg})$ was administered intraperitoneally once a week. Chimeric siRNA (1 mg/kg; RNAi Inc., Tokyo, Japan), a small interfering RNA/DNA chimera, was mixed with $\mathrm{CaP}$ hybrid micelles and injected into the tail vein three times a week. DOC $(2.5 \mathrm{mg} / \mathrm{kg})$ was administered intraperitoneally once weekly.

All animal experiments were performed with the approval of the Institutional Animal Care and Use Committee of the University of Tokyo, and adhered to the standards set for the use of mice in research. The detailed protocol is described in the Supplementary Methods. 


\section{Statistical analysis}

Mean values \pm standard deviations were compared using unpaired $t$-tests. For multiple comparisons, differences were determined using one-way analysis of variance (ANOVA) followed by Tukey's post-hoc test. $P<0.05$ was considered statistically significant.

For the Kaplan-Meier survival analyses, survival curves were compared using the logrank test for breast cancer patients or generalized Wilcoxon test for mouse cohorts.

\section{Abbreviations}

3'-UTR, 3' untranslated region; ABC, ATPbinding cassette; CaP, calcium phosphate; CDDP, cis-diamminedichloroplatinum; ChIP, chromatin immunoprecipitation; CK, cytokeratin; CSC, cancer stem cell; DMEM, Dulbecco's Modified Eagle Medium; DOC, docetaxel; DOX, doxorubicin; ES, embryonic stem; FBS, fetal bovine serum; GO, gene ontology; H3K4me3, histone H3 trimethyl Lys4; H3K27me3, histone H3 trimethyl Lys27; HER, human epidermal growth factor receptor; KD, knockdown; KO, knock-out; LGB, betalactoglobulin promoter; miRNA, microRNA; MMTV, mouse mammary virus tumor; PEG, polyethylene glycol; PEI, polyethyleneimine; PRDM14, PR (PRDI-BF1 and RIZ) domain zinc finger protein 14; qRT-PCR, quantitative real-time reverse transcription polymerase chain reaction; RNA Pol II, RNA polymerase II; RPMI, Roswell Park Memorial Institute; shRNA, short hairpin RNA; siRNA, small interfering RNA; TSS, transcription start site.

\section{Authors' contributions}

H.T. and C.M. wrote the manuscript, planned the experiments, and interpreted the data. H.T., D.H., C.M., and H.Z. conducted the experiments. H.T., D.H., and C.M. assessed the in vitro and in vivo experiments. H.T. and C.M. performed the NGS and FCM analyses. H.T. and C.M. analyzed the gene expression data and performed statistical analysis. H.Z. provided breast cancer samples and established primary cultures from the samples. N.N. and K.K. generated and provided the $\mathrm{CaP}$ hybrid micelles. H.T., H.Y., and K.I. supervised the experiments. All authors critically reviewed and approved the final manuscript.

\section{ACKNOWLEDGMENTS}

We wish to thank Dr. Yohei Miyagi from the Kanagawa Cancer Center for the clinical samples and the editors at DMC Corp. for help with editing the manuscript.

\section{CONFLICTS OF INTEREST}

None of the authors have any conflicts of interest to declare.

\section{FUNDING}

This work was supported by the Department of Research Promotion, Practical Research for Innovative Cancer Control, Ministry of Health, Labour and Welfare (H.T.). The Kanagawa Cancer Center Cancer Tissue Repository was supported by the Scientific Support Programs for Cancer Research, Grant-in-Aid for Scientific Research on Innovative Areas, Ministry of Education, Culture, Sports, Science, and Technology of Japan (Grant number: 221S0001).

\section{REFERENCES}

1. Visvader JE, Lindeman GJ. Cancer stem cells: current status and evolving complexities. Cell Stem Cell. 2012; 10:717-28.

2. Maccalli C, de Maria R. Cancer stem cells: perspectives for therapeutic targeting. Cancer Immunol Immunother. 2015; 64:91-7.

3. Al-Hajj M, Wicha MS, Benito-Hernandez A, Morrison SJ, Clarke MF. Prospective identification of tumorigenic breast cancer cells. Proc Natl Acad Sci USA. 2003;100:3982-88.

4. Yamaji M, Seki Y, Kurimoto K, Yabuta Y, Yuasa M, Shigeta M, Yamanaka K, Ohinata Y, Saitou M. Critical function of Prdm14 for the establishment of the germ cell lineage in mice. Nature Genetics. 2008; 40:1016-1022.

5. Yamaji M, Ueda J, Hayashi K, Ohta H, Yabuta Y, Kurimoto K, Nakato R, Yamada Y, Shirahige K, Saitou M. PRDM14 ensures naive pluripotency through dual regulation of signaling and epigenetic pathways in mouse embryonic stem cells. Cell Stem Cell. 2013; 12:368-82.

6. Chia NY, Chan YS, Feng B, Lu X, Orlov YL, Moreau D, Kumar P, Yang L, Jiang J, Lau MS, Huss M, Soh BS, Kraus P, et al. A genome-wide RNAi screen reveals determinants of human embryonic stem cell identity. Nature. 2010; 468:316-20.

7. Caretti G, Di Padova M, Micales B, Lyons GE, Sartorelli V. The Polycomb Ezh2 methyltransferase regulates muscle gene expression and skeletal muscle differentiation. Genes Dev. 2004; 18:2627-38.

8. Kalantry S, Mills KC, Yee D, Otte AP, Panning B, Magnuson T. The Polycomb group protein Eed protects the inactive $\mathrm{X}$-chromosome from differentiation-induced reactivation. Nat Cell Biol. 2006;8:195-202.

9. Shinkai Y, Tachibana M. H3K9 methyltransferase G9a and the related molecule GLP. Genes Dev. 2011; 25:781-8.

10. Bernstein BE, Mikkelsen TS, Xie X, Kamal M, Huebert DJ, Cuff J, Fry B, Meissner A, Wernig M, Plath K, Jaenisch R, Wagschal A, Feil R, et al. A bivalent chromatin structure marks key developmental genes in embryonic stem cells. Cell. 2006; 125:315-26.

11. Nishikawa N, Toyota M, Suzuki H, Honma T, Fujikane T, Ohmura T, Nishidate T, Ohe-Toyota M, Maruyama R, Sonoda T, Sasaki Y, Urano T, Imai K, et al. Gene 
amplification and overexpression of PRDM14 in breast cancers. Cancer Res. 2007; 67:9649-57.

12. Dettman EJ, Simko SJ, Ayanga B, Carofino BL, Margolin JF, Morse HC 3rd, Justice MJ. Prdm14 initiates lymphoblastic leukemia after expanding a population of cells resembling common lymphoid progenitors. Oncogene. 2011; 30:2859-73.

13. Zhang T, Meng L, Dong W, Shen H, Zhang S, Liu Q, $\mathrm{Du}$ J. High expression of PRDM14 correlates with cell differentiation and is a novel prognostic marker in resected non-small cell lung cancer. Med Oncol. 2013; 30:605.

14. Ui-Tei K, Naito $\mathrm{Y}$, Zenno S, Nishi K, Yamato K, Takahashi F, Juni A, Saigo K. Functional dissection of siRNA sequence by systematic DNA substitution: modified siRNA with a DNA seed arm is a powerful tool for mammalian gene silencing with significantly reduced offtarget effect. Nucleic Acids Res. 2008; 36:2136-51.

15. Yamato K, Egawa N, Endo S, Ui-Tei K, Yamada T, Saigo K, Hyodo I, Kiyono T, Nakagawa I. Enhanced specificity of HPV16 E6E7 siRNA by RNA-DNA chimera modification. Cancer Gene Ther. 2011; 18:587-97.

16. D'Alessandro-Gabazza CN, Kobayashi T, Boveda-Ruiz D, Takagi T, Toda M, Gil-Bernabe P, Miyake Y, Yasukawa A, Matsuda Y, Suzuki N, Saito H, Yano Y, Fukuda A, et al. Development and preclinical efficacy of novel transforming growth factor- $\beta 1$ short interfering RNAs for pulmonary fibrosis. Am J Respir Cell Mol Biol. 2012; 46:397-406.

17. Pittella F, Cabral H, Maeda Y, Mi P, Watanabe S, Takemoto H, Kim HJ, Nishiyama N, Miyata K, Kataoka K. Systemic siRNA delivery to a spontaneous pancreatic tumor model in transgenic mice by PEGylated calcium phosphate hybrid micelles. J Control Release. 2014; 178:18-24.

18. Aramaki S, Hayashi K, Kurimoto K, Ohta H, Yabuta Y, Iwanari H, Mochizuki Y, Hamakubo T, Kato Y, Shirahige K, Saitou M. A mesodermal factor, T, specifies mouse germ cell fate by directly activating germline determinants. Dev Cell. 2013; 27:516-529.

19. Arnold SJ, Stappert J, Bauer A, Kispert A, Herrmann BG, Kemler R. Brachyury is a target gene of the Wnt/betacatenin signaling pathway. Mech Dev. 2000; 91:249-58.

20. Li Y, Hively WP, Varmus HE. Use of MMTV-Wnt-1 transgenic mice for studying the genetic basis of breast cancer. Oncogene. 2000; 19:1002-9.

21. Cho RW, Wang X, Diehn M, Shedden K, Chen GY, Sherlock G, Gurney A, Lewicki J, Clarke MF. Isolation and molecular characterization of cancer stem cells in MMTVWnt-1 murine breast tumors. Stem Cells. 2008; 26:364-71.

22. Böcker W, Moll R, Poremba C, Holland R, Van Diest PJ, Dervan P, Bürger H, Wai D, Ina Diallo R, Brandt B, Herbst H, Schmidt A, Lerch MM, et al. Common adult stem cells in the human breast give rise to glandular and myoepithelial cell lineages: a new cell biological concept. Lab Invest. 2002; 82:737-46.

23. Prat A, Perou CM. Mammary development meets cancer genomics. Nat Med. 2009; 15:842-4.
24. Dean M, Fojo T, Bates S. Tumor stem cells and drug resistance. Nat Rev Cancer. 2005; 5:275-84.

25. Zhou S, Schuetz JD, Bunting KD, Colapietro AM, Sampath J, Morris JJ, Lagutina I, Grosveld GC, Osawa M, Nakauchi H, Sorrentino BP. The ABC transporter Bcrp1/ $\mathrm{ABCG} 2$ is expressed in a wide variety of stem cells and is a molecular determinant of the side-population phenotype. Nat Med. 2001; 7:1028-34

26. Dougall WC. Molecular pathways: osteoclast-dependent and osteoclast-independent roles of the RANKL/RANK/ OPG pathway in tumorigenesis and metastasis. Clin Cancer Res. 2012; 18:326-35.

27. Kendellen MF, Bradford JW, Lawrence CL, Clark KS, Baldwin AS. Canonical and non-canonical NF- $\kappa$ B signaling promotes breast cancer tumor-initiating cells. Oncogene. 2014; 33:1297-305.

28. Liu C, Kelnar K, Liu B, Chen X, Calhoun-Davis T, Li $\mathrm{H}$, Patrawala L, Yan H, Jeter C, Honorio S, Wiggins JF, Bader AG, Fagin R, et al. The microRNA miR-34a inhibits prostate cancer stem cells and metastasis by directly repressing CD44. Nat Med. 2011; 17:211-5.

29. Wu MY, Fu J, Xiao X, Wu J, Wu RC. MiR-34a regulates therapy resistance by targeting HDAC1 and HDAC7 in breast cancer. Cancer Lett. 2014; 354:311-9.

30. Marcato P, Dean CA, Liu RZ, Coyle KM, Bydoun M, Wallace M, Clements D, Turner C, Mathenge EG, Gujar SA, Giacomantonio CA, Mackey JR, Godbout R, et al. Aldehyde dehydrogenase 1A3 influences breast cancer progression via differential retinoic acid signaling. Mol Oncol. 2015; 9:17-31.

31. Bailey TL, Boden M, Buske FA, Frith M, Grant CE, Clementi L, Ren J, Li WW, Noble WS. MEME SUITE: tools for motif discovery and searching. Nucleic Acids Res. 2009;37:202-8.

32. Ma Z, Swigut T, Valouev A, Rada-Iglesias A, Wysocka J. Sequence-specific regulator PRDM14 safeguards mouse ESCs from entering extraembryonic endoderm fates. Nat Struct Mol Biol. 2011; 18:120-7.

33. Li Q, Lian S, Dai Z, Xiang Q, Dai X. BGDB: a database of bivalent genes. Database (Oxford). 2013; bat057.

34. Mayr C, Bartel DP. Widespread shortening of 3'UTRs by alternative cleavage and polyadenylation activates oncogenes in cancer cells. Cell. 2009; 138:673-84.

35. Lembo A, Di Cunto F, Provero P. Shortening of 3'UTRs correlates with poor prognosis in breast and lung cancer. PLoS One. 2012; 7:e31129.

36. Tassone P, Tagliaferri P, Perricelli A, Blotta S, Quaresima B, Martelli ML, Goel A, Barbieri V, Costanzo F, Boland CR, Venuta S. BRCA1 expression modulates chemosensitivity of BRCA1-defective HCC1937 human breast cancer cells. Br J Cancer. 2003; 88:1285-91.

37. Liu S, Ballian N, Belaguli NS, Patel S, Li M, Templeton NS, Gingras MC, Gibbs R, Fisher W, Brunicardi FC. PDX1 acts as a potential molecular target for treatment of human pancreatic cancer. Pancreas. 2008;37:210-20. 
38. Quintana E, Shackleton M, Sabel MS, Fullen DR, Johnson TM, Morrison SJ. Efficient tumour formation by single human melanoma cells. Nature. 2008; 456:593-8.

39. Ishizawa K, Rasheed ZA, Karisch R, Wang Q, Kowalski J, Susky E, Pereira K, Karamboulas C, Moghal N, Rajeshkumar NV, Hidalgo M, Tsao M, Ailles L, et al. Tumor-initiating cells are rare in many human tumors. Cell Stem Cell. 2010; 7:279-82.

40. Gobelbiewska A, Brons NH, Bjerkvig R, Niclou SP. Critical appraisal of the side population assay in stem cell and cancer stem cell research. Cell Stem Cell. 2011; 8:136-47.

41. Ohmori T, Yang JL, Price JO, Arteaga CL. Blockade of tumour cell transforming growth factor-betas enhances cell cycle progression and sensitizes human breast carcinoma cells to cytotoxic chemotherapy. Exp Cell Res. 1998; 245:350-9.

42. Weaver VM, Lelièvre S, Lakins JN, Chrenek MA, Jones JC, Giancotti F, Werb Z, Bissell MJ. beta4 integrin-dependent formation of polarized three-dimensional architecture confers resistance to apoptosis in normal and malignant mammary epithelium. Cancer Cell. 2002; 2:205-16.

43. Li Q, Chow AB, Mattingly RR. Three-dimensional overlay culture models of human breast cancer reveal a critical sensitivity to mitogen-activated protein kinase kinase inhibitors. J Pharmacol Exp Ther. 2009; 332:821-8.

44. Birgersdotter A, Sandberg R, Ernberg I. Gene expression perturbation in vitro--a growing case for three-dimensional (3D) culture systems. Semin Cancer Biol. 2005; 15:405-12.

45. Oskarsson $\mathrm{T}$, Acharyya S, Zhang XH, Vanharanta S, Tavazoie SF, Morris PG, Downey RJ, Manova-Todorova K, Brogi E, Massagué J. Breast cancer cells produce tenascin C as a metastatic niche component to colonize the lungs. Nat Med. 2011; 17:867-74.

46. Reim F, Dombrowski Y, Ritter C, Buttmann M, Häusler S, Ossadnik M, Krockenberger M, Beier D, Beier CP, Dietl J, Becker JC, Hönig A, Wischhusen J. Immunoselection of breast and ovarian cancer cells with trastuzumab and natural killer cells: selective escape of CD44high/CD24low/HER2low breast cancer stem cells. Cancer Res. 2009; 69:8058-66.

47. Alsuliman A, Colak D, Al-Harazi O, Fitwi H, Tulbah A, AlTweigeri T, Al-Alwan M, Ghebeh H. Bidirectional crosstalk between PD-L1 expression and epithelial to mesenchymal transition: significance in claudin-low breast cancer cells. Mol Cancer. 2015; 14:149.

48. Shipitsin M, Campbell LL, Argani P, Weremowicz S, Bloushtain-Qimron N, Yao J, Nikolskaya T, Serebryiskaya T, Beroukhim R, Hu M, Halushka MK, Sukumar S, Parker LM, et al. Molecular definition of breast tumor heterogeneity. Cancer Cell. 2007; 11:259-73

49. Ishimoto T, Nagano O, Yae T, Tamada M, Motohara T, Oshima H, Oshima M, Ikeda T, Asaba R, Yagi H, Masuko T,
Shimizu T, Ishikawa T, et al. CD44 variant regulates redox status in cancer cells by stabilizing the xCT subunit of system $\mathrm{xc}(-)$ and thereby promotes tumor growth. Cancer Cell. 2011; 19:387-400

50. Marotta LL, Almendro V, Marusyk A, Shipitsin M, Schemme J, Walker SR, Bloushtain-Qimron N, Kim JJ, Choudhury SA, Maruyama R, Wu Z, Gönen M, Mulvey LA, et al. The JAK2/STAT3 signaling pathway is required for growth of CD44-CD24- stem cell-like breast cancer cells in human tumors. J Clin Invest. 2011; 121:2723-35.

51. Chan YS, Göke J, Lu X, Venkatesan N, Feng B, Su IH, $\mathrm{Ng} \mathrm{HH}$. A PRC2-dependent repressive role of PRDM14 in human embryonic stem cells and induced pluripotent stem cell reprogramming. Stem Cells. 2013; 31:682-92.

52. Robertson KD, Uzvolgyi E, Liang G, Talmadge C, Sumegi J, Gonzales FA, Jones PA. The human DNA methyltransferases (DNMTs) 1, 3a and 3b: coordinate mRNA expression in normal tissues and overexpression in tumors. Nucleic Acids Res. 1999; 27:2291-8.

53. Sauvageau M, Sauvageau G. Polycomb group proteins: multi-faceted regulators of somatic stem cells and cancer. Cell Stem Cell. 2010; 7:299-313.

54. Ohm JE, McGarvey KM, Yu X, Cheng L, Schuebel KE, Cope L, Mohammad HP, Chen W, Daniel VC, Yu W, Berman DM, Jenuwein T, Pruitt K, et al. A stem cell-like chromatin pattern may predispose tumor suppressor genes to DNA hypermethylation and heritable silencing. Nat Genet. 2007; 39:237-42.

55. Chapman-Rothe N, Curry E, Zeller C, Liber D, Stronach E, Gabra H, Ghaem-Maghami S, Brown R. Chromatin H3K27me3/H3K4me3 histone marks define gene sets in high-grade serous ovarian cancer that distinguish malignant, tumour-sustaining and chemo-resistant ovarian tumour cells. Oncogene. 2013; 32:4586-92.

56. Grelier G, Voirin N, Ay AS, Cox DG, Chabaud S, Treilleux I, Léon-Goddard S, Rimokh R, Mikaelian I, Venoux C, Puisieux A, Lasset C, Moyret-Lalle C. Prognostic value of Dicer expression in human breast cancers and association with the mesenchymal phenotype. Br J Cancer. 2009; 101:673-83.

57. Merritt WM, Lin YG, Han LY, Kamat AA, Spannuth WA, Schmandt R, Urbauer D, Pennacchio LA, Cheng JF, Nick AM, Deavers MT, Mourad-Zeidan A, Wang H, et al. Dicer, Drosha, and outcomes in patients with ovarian cancer. N Engl J Med. 2008; 359:2641-50.

58. Virant-Klun I, Stimpfel M, Cvjeticanin B, VrtacnikBokal E, Skutella T. Small SSEA-4-positive cells from human ovarian cell cultures: related to embryonic stem cells and germinal lineage? J Ovarian Res. 2013; 6:24. 